\title{
Nitrous Oxide Fuels Blends: Research on premixed Monopropellants at the German Aerospace Center (DLR) since 2014
}

\author{
Lukas Werling ${ }^{1}$, Till Hörger ${ }^{2}$, Konstantin Manassis ${ }^{3}$, Daniel \\ Grimmeisen ${ }^{4}$, Marius Wilhelm ${ }^{5}$, Chiara Erdmann ${ }^{6}$, Helmut Ciezki ${ }^{7}$, \\ Stefan Schlechtriem ${ }^{8}$ \\ German Aerospace Center (DLR), Institute of Space Propulsion, D-74239 Hardthausen,
} Germany

\author{
Sandra Richter ${ }^{9}$, Torsten Methling ${ }^{10}$, Elke Goos $^{11}$, Corina Janzer ${ }^{12}$ \\ Clemens Naumann ${ }^{13}$
}

German Aerospace Center (DLR), Institute of Combustion Technology, D-70569 Stuttgart, Germany

\author{
Uwe Riedel ${ }^{14}$ \\ German Aerospace Center (DLR), Institute of Low-Carbon Industrial Processes, D-03046 \\ Cottbus, Germany
}

\begin{abstract}
In 2014 DLR started research activities focused on premixed monopropellants consisting of nitrous oxide and hydrocarbons. Those propellants offer promising characteristics as they are non-toxic, deliver a high $I_{s p}$ consist of components with low cost and could simplify a propulsion system due to self-pressurized operation. Initially DLR chose a mixture of nitrous oxide $\left(\mathrm{N}_{2} \mathrm{O}\right)$ and ethene $\left(\mathrm{C}_{2} \mathrm{H}_{4}\right)$. In the course of the project, a mixture of nitrous oxide and ethane $\left(\mathrm{C}_{2} \mathrm{H}_{6}\right)$ was included to the research activities. The activities are part of DLR's Future Fuels project and divided into five main parts: 1) investigations of the combustion behavior of the propellant in a rocket combustor, 2) testing and developing of flame arresters, 3) development and reduction of reaction mechanisms, 4) numerical simulations of the combustion process and 5) basic miscibility investigations. The emphasis within the project is on the first three tasks, while the last two tasks are used to widen the knowledge about the
\end{abstract}

\footnotetext{
${ }^{1}$ Head Facilities Group, Propellants Department, AIAA Member.

${ }^{2}$ Student Researcher, Propellants Department.

${ }^{3}$ Research Engineer, Propellants Department, AIAA Member.

${ }^{4}$ Student Researcher, Propellants Department.

${ }^{5}$ Research Engineer, Propellants Department, AIAA Member.

${ }^{6}$ Student Researcher, Propellants Department.

${ }^{7}$ Head propellants Department. AIAA Senior Member

${ }^{8}$ Director Institute of Space Propulsion.

${ }^{9}$ Postdoctoral researcher, Chemical Kinetics and Analytics Department.

${ }^{10}$ Head Chemical Kinetic Modelling Group, Chemical Kinetics and Analytics Department.

${ }^{11}$ Research Scientist, Chemical Kinetics and Analytics Department.

${ }^{12}$ Postdoctoral researcher, Chemical Kinetics and Analytics Department.

${ }^{13}$ Head Experimental Reaction Kinetics, Chemical Kinetics and Analytics Department.

${ }^{14}$ Acting Director, Institute of Low-Carbon Industrial Processes, former head of Chemical Kinetics Department.
} 
propellant's physical and combustion properties. The following paper will give a short summary of the activities carried out within the projects and focus on selected results regarding premixed propellants.

\section{Nomenclature}

\begin{tabular}{|c|c|}
\hline$A D N$ & $=$ Ammonium dinitramid \\
\hline$c^{*}{ }_{\exp }$ & $=$ Experimentally measured $\mathrm{c}^{*}[\mathrm{~m} / \mathrm{s}]$ \\
\hline$c *_{\text {theo }}$ & $=$ Calculated, theoretical $\mathrm{c}^{*}[\mathrm{~m} / \mathrm{s}]$ \\
\hline$C F D$ & $=$ Computational fluid dynamics \\
\hline$D L R$ & $=$ German Aerospace Center (Deutsches Zentrum für Luft- und Raumfahrt) \\
\hline$d_{t h}$ & $=$ Nozzle throat diameter $[\mathrm{m}]$ \\
\hline$H A N$ & $=$ Hydroxylammonium nitrate \\
\hline HyNOx & $=$ Hydrocarbons mixed with Nitrous Oxide \\
\hline$I_{s p}$ & $=$ specific impulse $[\mathrm{s}]$ \\
\hline ISS & $=$ International Space Station \\
\hline$L^{*}$ & $=$ Characteristic combustion chamber length $[\mathrm{m}]$ \\
\hline NOFB & $=$ Nitrous Oxide Fuel Blends \\
\hline$p_{c}$ & $=$ Combustion chamber pressure $[\mathrm{bar}]$ \\
\hline$R O F$ & $=$ Mass related mixture ratio Oxidizer/Fuel \\
\hline \multicolumn{2}{|c|}{ Greek symbols } \\
\hline$\Delta p$ & $=$ Pressure drop of porous material [bar] \\
\hline$\eta_{c^{*}}$ & $=c^{*}$ efficiency or combustion efficiency \\
\hline$\varphi$ & $=$ Fuel-oxidizer equivalence ratio \\
\hline
\end{tabular}

\section{Introduction and Motivation}

To this day, hydrazine $\left(\mathrm{N}_{2} \mathrm{H}_{4}\right)$ is the most widely used monopropellant for space applications. The propellant offers advantages like long-term storability, is cold-start capable via catalyst and delivers sufficient performance. Furthermore hydrazine propulsion systems are robust and highly reliable, which is critical for long term missions and manned space flight [1].

Despite these advantages the use of hydrazine is associated with some major drawbacks: $\mathrm{N}_{2} \mathrm{H}_{4}$ is highly toxic and carcinogenic. Thus for handling and transportation of hydrazine extensive safety measures have to be observed. These safety measures cause high personnel and equipment costs e.g. during fueling of a spacecraft or testing and qualification of a propulsion system.

Induced by the mentioned serious health risks and the related costs of hydrazine handling, a worldwide quest for so called green monopropellants is ongoing. Several green propellant alternatives with different levels of maturation are currently under investigation, in development or already used in spacecraft [2].

The most advanced green propellant is LMP-103S, based on the energetic salt ADN (ammonium dinitramid) and developed by the Swedish company Bradford ECAPS [3]. Currently, LMP-103S based propulsion systems are used on 13 Sky-Sat satellites in orbit, the propulsion system of each satellite is equipped with four $1 \mathrm{~N}$ thrusters [4]. The main advantages of LMP-103S are the lower toxicity and thus the easier handling, the higher density (+ $24 \%$ compared to hydrazine) and increased specific impulse ( $\mathrm{I}_{\mathrm{sp}} \mathrm{LMP} 103 \mathrm{~S}=254 \mathrm{~s},+6 \%$ compared to hydrazine) [5]. Disadvantages of LMP are the increased propellant costs, the higher combustion temperatures, which require more advanced combustion chamber materials (Iridium/Rhenium) and the need for a preheated catalyst $\left(340^{\circ} \mathrm{C}\right.$ to $360^{\circ} \mathrm{C}$ ) $[4,6]$.

With focus on lower cost and low toxicity, highly concentrated hydrogen peroxide $\left(\mathrm{H}_{2} \mathrm{O}_{2}\right)$ might also be a suitable green propellant alternative. The use of $\mathrm{H}_{2} \mathrm{O}_{2}$ as monopropellant for space applications has a long history [7]. In the early days of space flight $\mathrm{H}_{2} \mathrm{O}_{2}$ was used for orbital control e.g. for the mercury capsule [8]. During the 1970s $\mathrm{H}_{2} \mathrm{O}_{2}$ was replaced by hydrazine in the USA due to the higher performance of $\mathrm{N}_{2} \mathrm{H}_{4}$. Nevertheless, some spacecraft still use $\mathrm{H}_{2} \mathrm{O}_{2}$ as monopropellant e.g. the gas generator of the Soyuz rocket and the attitude control system of the Soyuz capsule operate with hydrogen peroxide [9]. The advantages of $\mathrm{H}_{2} \mathrm{O}_{2}$ are its low toxicity, easy ignitability via catalyst and the well-known chemical and physical properties. Furthermore hydrogen peroxide is a suitable oxidizer in green bipropellant systems [10]. Disadvantages of $\mathrm{H}_{2} \mathrm{O}_{2}$ are its low performance $\left(\mathrm{I}_{\mathrm{sp}}=185 \mathrm{~s}\right)$, the 
danger of explosive decomposition, the catalytic reaction of peroxide with typical spacecraft materials (e.g. Titanium alloys) and the slow decomposition in storage tanks [11, 12]. Nevertheless for short term bipropellant applications $\mathrm{H}_{2} \mathrm{O}_{2}$ seems to be a proper, green oxidizer.

In the USA, China, Russia and in Japan another class of propellants are studied intensively: green propellants based on HAN (hydroxylammonium nitrate). Those propellants offer low toxicity due to negligible vapor pressures and higher performance. Depending on the specific propellant formulation an $\mathrm{I}_{\mathrm{sp}}$ of $248 \mathrm{~s}$ for AFM-315E [13, 14] to $276 \mathrm{~s}$ for SHP 163 [15] could be achieved. A further advantage of HAN-based propellants are their high density (up to $\left.1400 \mathrm{~kg} / \mathrm{m}^{3}[15]\right)$. The performance benefits of HAN-based propellants are caused by high combustion temperatures, which are challenging for catalyst and combustion chamber material. Furthermore the high energy content and the corresponding explosion hazards are drawbacks of HAN-based monopropellants [16]. A test flight of an AFM-315E based propulsion system was launched in June 2019 with NASAs Green Propellant Infusion Mission (GPIM).

Another approach to replace conventional toxic propellants are the so called "water electrolysis propulsion systems" [17-19]. Those propulsion systems consist of a water tank, a hydrogen and an oxygen tank, an electrolyzer and a thruster equipped with a suitable catalyst. In orbit the electrolyzer decomposes the water into hydrogen and oxygen. The gaseous hydrogen and oxygen are stored in separate tanks and used for thrusters at a low oxidizer to fuel mixture ratio or with a suitable cooling system to assure low combustion temperatures. In the case of the low mixture ratio operation the excess oxygen could be used for oxygen supply of a space station or used in cold gas thrusters. The specific impulse of a water propulsion system depends on the mode of operation but easily values greater than $300 \mathrm{~s}$ can be achieved. Disadvantages of water propulsion systems are a considerable complexity, the limited amount of gaseous $\mathrm{H}_{2}$ and $\mathrm{O}_{2}$ which have to be stored in separate tanks and a low $\mathrm{H}_{2} / \mathrm{O}_{2}$ production rate of the electrolyzer. Due to the low production rate of gaseous $\mathrm{H}_{2}$ and $\mathrm{O}_{2}$ the propulsion system is suitable only for low thrust applications.

Another promising category of low cost and high performance green propellants are mixtures of nitrous oxide $\left(\mathrm{N}_{2} \mathrm{O}\right)$ and fuels, also known as nitrous oxide fuel blends [20-23]. The following paragraph will give a short overview of the research activities concerning those propellants. Furthermore DLR's research on green propellants consisting of nitrous oxide and ethene $\left(\mathrm{C}_{2} \mathrm{H}_{4}\right)$ and ethane $\left(\mathrm{C}_{2} \mathrm{H}_{6}\right)$ will be introduced.

\section{A. Nitrous Oxide Fuel Blends (NOFB)/Hydrocarbons mixed with Nitrous Oxide (HyNOx)}

In contrast to conventional monopropellants like hydrazine $\left(\mathrm{N}_{2} \mathrm{H}_{4}\right)$ or hydrogen peroxide $\left(\mathrm{H}_{2} \mathrm{O}_{2}\right)$ nitrous oxide fuel blends do not consist of one single substance. Instead those propellants are mixtures of $\mathrm{N}_{2} \mathrm{O}$ as oxidizer and one or more fuel(s). The propellants components are liquefiable under pressure and thus the propellant can be stored in liquid state in a tank. Due to the premixed state, those propellants are also called premixed monopropellants [24]. A big advantage of nitrous oxide fuel blends is their bipropellant like performance ( $\mathrm{Isp}_{\mathrm{s}} \geq 300 \mathrm{~s}$ ), while using cheap and non-toxic components. Nitrous oxide and light hydrocarbons are available worldwide at low cost and can easily be shipped to launch sites. Furthermore due to the high vapor pressure of $\mathrm{N}_{2} \mathrm{O}$ self-pressurized propulsion systems could be realized.

Table 1: Advantages and disadvantages of Nitrous Oxide Fuel Blends compared to conventional monopropellants

\begin{tabular}{c|c}
\multicolumn{1}{c|}{ Advantages } & Disadvantages \\
\hline$+\quad \mathrm{I}_{\mathrm{sp}} \geq 300 \mathrm{~s}$ & $-\begin{array}{l}\text { Danger of flame flashback and explosion of } \\
\text { propellant }\end{array}$ \\
\hline$+\quad$ Non-toxic & $\begin{array}{l}\text { Density lower than hydrazine: } 0.7-0.8 \\
\mathrm{~kg} / \mathrm{m}^{3}\end{array}$ \\
\hline$+\quad$ Cheap components & $\begin{array}{l}\text { Higher tank and feeding line pressure than } \\
\text { conventional monopropellant-systems }\end{array}$ \\
\hline$+\quad$ Self-pressurization of propulsion system possible & $-\begin{array}{l}\text { High combustion temperatures in the range } \\
\text { of 3000 K }\end{array}$ \\
\hline$+\quad \begin{array}{l}\text { For precise, low thrust maneuvers the propellant } \\
\text { can be used as cold-gas propellant }\end{array}$ & \\
\hline$+\quad$ Ignitable via spark or high temperature glow plug & \\
\hline$+\quad$ Regenerative cooling possible &
\end{tabular}


In contrast to those benefits, the main challenges concerning mixtures of $\mathrm{N}_{2} \mathrm{O}$ and fuels are high combustion temperatures and the danger of a flashback across the injection system in the tank structure. If a flame flashback occurs, the destruction of the tank and the whole propulsion system is very likely. Thus the propulsion system of a premixed propellant needs to be equipped with a suitable flame arrester.

Table 1 lists the characteristic advantages and disadvantages of Nitrous Oxide Fuel Blends/Hydrocarbons mixed with Nitrous Oxide compared to conventional monopropellants

First investigations concerning premixed propellants took place during World War II [25]. In those days mixtures of hydrogen peroxide and ethanol were investigated. However, these mixtures were very sensitive and lead to several accidents with fatalities. Thus handling of premixed monopropellants is a challenging and dangerous task and the safety and sensitivity of the propellant should be addressed early on during the research activities. More recently the company Firestar/ISPS developed a premixed monopropellant based on nitrous oxide and ethine, ethene and ethane called NOFBX [23]. NOFBX was supposed to be tested aboard the ISS in the year 2012, but since then no new publication or information has become available.

Followed by the developments at Firestar, DARPA started the investigation of a $\mathrm{N}_{2} \mathrm{O} / \mathrm{C}_{2} \mathrm{H}_{2}$ propellant called NA7 [24]. The propellant should be used to power rockets with small satellites while the rocket should be launched from an F-15 fighter jet. Due to two explosions during ground tests the activities concerning NA-7 were stopped [24].

In the EU TNO, Bradford Engineering and Nammo Westcott investigated at premixed propellant consisting of nitrous oxide and ethanol in the framework of an ESA contract [26-28]. During the activity the miscibility of the components was investigated, a system study was conducted and the propellant was test in hot gas combustion tests. Due to high combustion temperatures the injector head was damaged during the hot fire tests and in sum only 3 tests could be conducted $[26,28]$.

\section{B. Research at DLR concerning $\mathrm{N}_{2} \mathrm{O} / \mathrm{C}_{2} \mathrm{H}_{4}$ and $\mathrm{N}_{2} \mathrm{O} / \mathrm{C}_{2} \mathrm{H}_{6}$ propellant mixtures}

DLR started its research activities in the field of premixed nitrous oxide/hydrocarbon propellants in the year 2014. Within the DLR internal project "Future Fuels" [29, 30] the activities will be ongoing until the end of 2021. During the first part of the project, a propellant consisting of $\mathrm{N}_{2} \mathrm{O} / \mathrm{C}_{2} \mathrm{H}_{4}$ was investigated; recently the investigation was extended to a mixture of $\mathrm{N}_{2} \mathrm{O}$ and $\mathrm{C}_{2} \mathrm{H}_{6}$. DLR calls the investigated propellant mixtures "Hydrocarbons mixed with Nitrous Oxide" (HyNOx).

The research activities are focused on five main areas, Fig. 1 shows those areas, the main aims and their interconnection. On the left hand side the first work page is shown: development and testing of combustion chambers and experimental thrusters. Here the propellant mixture is combusted in a rocket combustor at DLR's M11 test bench in Lampoldshausen [31,32]. The aim of the combustion tests is to analyze the general propellant performance, to test different ignition methods, to investigate the heat loads on the chamber walls and to evaluate suitable flashback arresters in a propulsion system environment.

Since flame arresters are a critical component of a future propulsion system, a second work package is dedicated to the investigation of the flame propagation processes and flame flashback mechanisms of the gaseous propellant. To conduct the corresponding experiments a test setup called "ignition test section" was used.

A third work package is dealing with the development of reaction mechanisms for the combustion of $\mathrm{N}_{2} \mathrm{O} / \mathrm{C}_{2} \mathrm{H}_{4}$ and $\mathrm{N}_{2} \mathrm{O} / \mathrm{C}_{2} \mathrm{H}_{6}$. The main goals of this work package are the experimental determination of ignition delay times, laminar flame speeds and the development of optimized and reduced reaction mechanisms. The reaction mechanisms are used for calculation of the flame properties as e.g. the laminar flame speed and the quenching diameters. Furthermore the reaction mechanisms are reduced to be suitable for CFD simulations.

The conduction of CFD simulations are part of a fourth work package. In the frame of this activity the transient combustion process of the propellant mixture in the ignition test setup was simulated. These simulations were used to gain a better understanding of the ongoing processes after ignition and during the flame propagation. Furthermore the numerical results (e.g. the flame propagation speed) were compared to the experimental observations to evaluate the reaction mechanisms.

The last work package comprises investigations of the liquefied propellant mixture. A miscibility setup was designed and constructed to analyze the propellant's behavior during mixing of $\mathrm{N}_{2} \mathrm{O}$ and $\mathrm{C}_{2} \mathrm{H}_{6}$. Additionally the setup will be used to assess if a phase separation or a de-mixing takes place. 


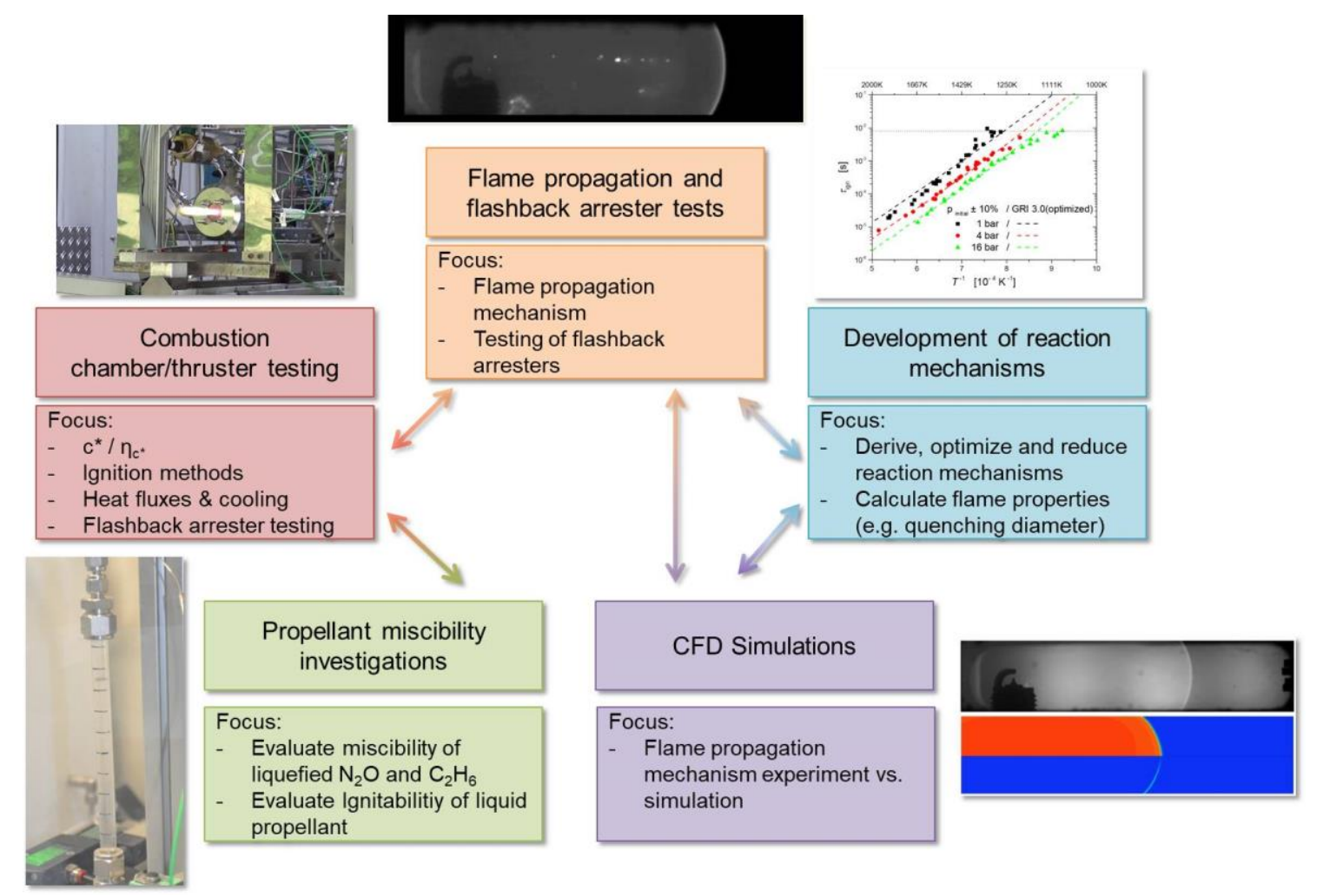

Fig. 1: DLR's research activities on $\mathrm{N}_{2} \mathrm{O} / \mathrm{C}_{2} \mathrm{H}_{4}$ and $\mathrm{N}_{2} \mathrm{O} / \mathrm{C}_{2} \mathrm{H}_{6}$ green propellants and their interconnection

Fig. 2 shows the timeline of the project, starting with initial investigations in 2014. To gain a basic experience about a $\mathrm{N}_{2} \mathrm{O} / \mathrm{C}_{2} \mathrm{H}_{4}$ propellant, first a rocket combustor test bench was set up. In parallel the experimental investigations concerning the reaction mechanisms started. First hot gas combustion tests in 2015 showed that suitable flashback arresters are indispensable to assure a safe operation of the experimental combustor. Thus investigation of the flame propagation processes and flame arresters started at the end of 2015. After first test series with different flame arresters the gained knowledge was used to perform a second combustor test campaign in 2016/2017. During this test campaign the performance of the propellant was investigated in detail. When the first reaction mechanisms were available in 2017, the models were used to conduct CFD simulations of the ignition and flame propagation processes. In addition to the simulation's results, a second flashback and ignition test campaign with an improved setup was conducted in 2017/2018. The results were then used to derive selection criteria for flame arresters.

In the year 2018 the investigations regarding the reaction mechanisms of $\mathrm{N}_{2} \mathrm{O} / \mathrm{C}_{2} \mathrm{H}_{6}$ propellants were started. Additionally in 2018 a test campaign with a regenerative cooled combustion chamber was conducted. During this test campaign $\mathrm{N}_{2} \mathrm{O} / \mathrm{C}_{2} \mathrm{H}_{4}$ and $\mathrm{N}_{2} \mathrm{O} / \mathrm{C}_{2} \mathrm{H}_{6}$ propellants were used. Because the $\mathrm{N}_{2} \mathrm{O} / \mathrm{C}_{2} \mathrm{H}_{6}$ propellant did not show any coking in the cooling channels during the test campaign, the focus of the investigations shifted to this propellant.

With the successful test campaign of a regenerative cooled combustion chamber, an improved combustor was designed and built in 2019/2020 and is no ready for testing. In addition the propellant miscibility investigations were started at the end of 2019 and are still ongoing. Additional research activities concerning $\mathrm{N}_{2} \mathrm{O} / \mathrm{C}_{2} \mathrm{H}_{6}$ propellants started in mid-2020 in the framework of the ESA activity "High Performance Propellant Development". 


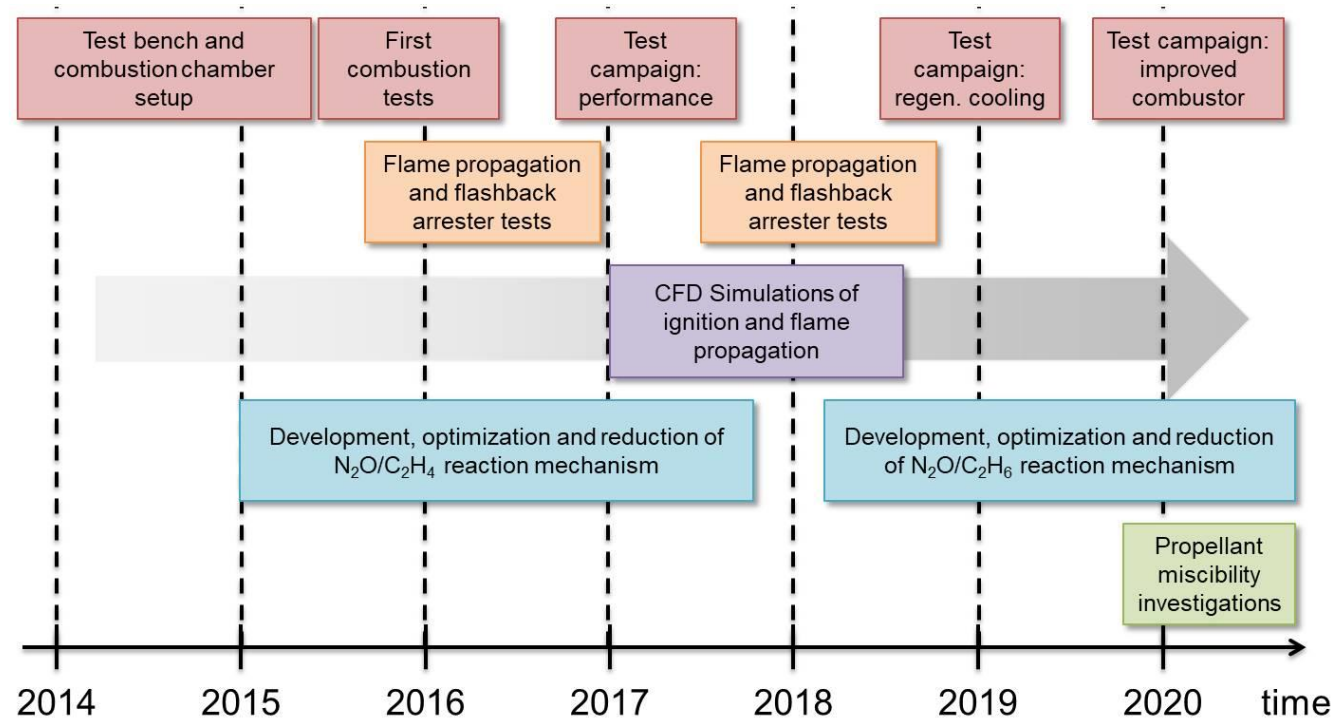

Fig. 2: Timeline of DLR's investigations on $\mathrm{N}_{2} \mathrm{O} / \mathrm{C}_{2} \mathrm{H}_{4}$ and $\mathrm{N}_{2} \mathrm{O} / \mathrm{C}_{2} \mathrm{H}_{6}$ propellants

\section{Selected results of the experimental and numerical investigations}

The following chapter will give a selection of the project's results and highlights. For each of to the five work packages (see Fig. 1) several results and highlights are shown and described. For detailed information please refer to the respective publications.

\section{A. Combustion chamber/thruster testing}

At the beginning of the project, a modular combustion chamber was designed. The capacitive cooled chamber consists of exchangeable segments made of a copper alloy $(\mathrm{CuCrZr})$. The modular chamber allows the investigation of the characteristic combustion chamber length $L^{*}$, the examination of different ignition methods $\left(\mathrm{H}_{2} / \mathrm{O}_{2}\right.$ torch, spark and glow plug) and the analysis of various injector geometries and sizes. The combustion chamber segments are equipped with pressure and temperature sensors to determine the chamber pressure and temperature during the hot runs. The pressure and temperature data were used to calculate the characteristic exhaust velocity $\mathrm{c}^{*}$, the combustion efficiency $\eta_{\mathrm{c}^{*}}$ and the heat flux to the chamber walls [33-38]. The combustion chamber was designed for gaseous mass flows of $\mathrm{N}_{2} \mathrm{O} / \mathrm{C}_{2} \mathrm{H}_{4}$ and $\mathrm{N}_{2} \mathrm{O} / \mathrm{C}_{2} \mathrm{H}_{6}$ in between $3 \mathrm{~g} / \mathrm{s}$ and $30 \mathrm{~g} / \mathrm{s}$. Fig. 3 gives a sectional view of the combustion chamber and shows the main parts of the chamber. A typical image of a hot gas test with the combustor is presented in Fig. 4. To date, more than 700 combustion tests with different versions of the combustion chamber have been carried out using $\mathrm{N}_{2} \mathrm{O} / \mathrm{C}_{2} \mathrm{H}_{4}$ or $\mathrm{N}_{2} \mathrm{O} / \mathrm{C}_{2} \mathrm{H}_{6}$ propellants [33-38]. 


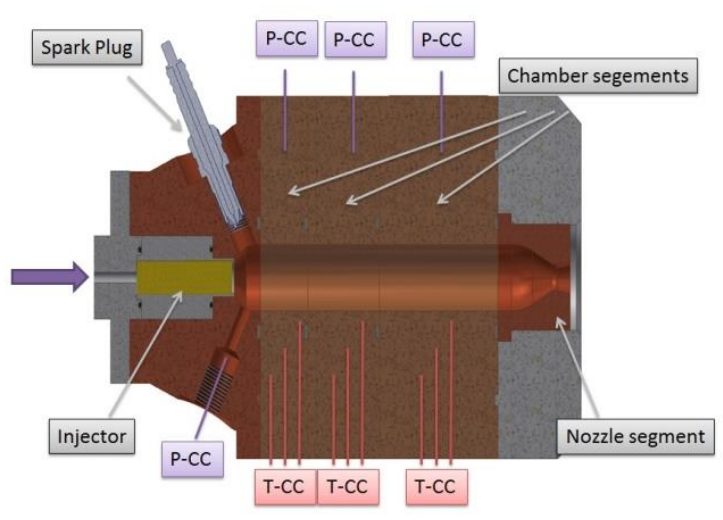

Fig. 3: Sectional view of capacitive cooled combustor [37]

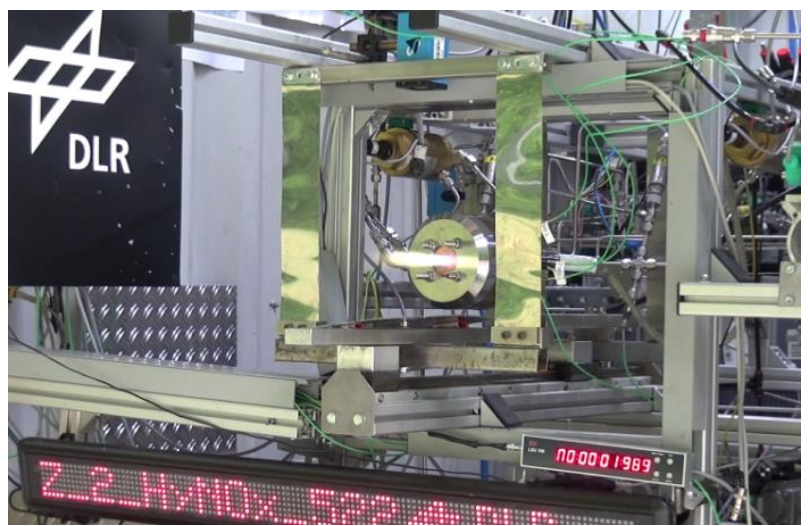

Fig. 4: Hot fire test of capacitive cooled combustor

During the test campaigns the influence of the mass flow, the oxidizer/fuel mixture ratio, the chamber length, the nozzle diameter and the injection system on $\mathrm{c}^{*}$, on $\eta_{\mathrm{c}^{*}}$ and on the heat flux to the chamber walls was studied [36, 37]. Furthermore a $\mathrm{H}_{2} / \mathrm{O}_{2}$ torch igniter, spark plugs and glow plugs were used to light the propellant mixture [3638]. Due to the good reproducibility and simplicity later versions of the combustion chamber were equipped with spark and glow plugs only.

\section{Characteristic exhaust velocity $c^{*}$ and combustion efficiency $\eta_{c^{*}}$}

Fig. 5 shows the characteristic exhaust velocity $c^{*}$ depending on the mass related oxidizer to fuel mixture ratio (ROF) of gaseous $\mathrm{N}_{2} \mathrm{O} / \mathrm{C}_{2} \mathrm{H}_{4}$ propellant. The red circles are the experimentally determined $\mathrm{c}^{*}$ values, the black squares are the theoretical $\mathrm{c}^{*}$ values obtained by NASA CEA [39]. The dotted blue line indicates the stoichiometric mixture ratio ( $\mathrm{ROF}=9.41)$. For the shown test campaign the chamber pressure, the nozzle throat diameter and the chamber length was kept constant to investigate the influence of the mixture ratio only. The location of the highest experimental c* $(1530 \mathrm{~m} / \mathrm{s})$ was obtained for a mixture ratio (ROF) of approximately 7 , which agrees well with the position of the theoretical predicted maximum $c^{*}(1650 \mathrm{~m} / \mathrm{s})$. The combustion efficiencies $\eta_{\mathrm{c}^{*}}$ for the test series were in between $92 \%-96 \%$.

Fig. 6 gives the experimental and theoretical $\mathrm{c}^{*}$ depending on combustion chamber pressure. To analyze the influence of the chamber pressure only, the mixture ratio, the chamber length and nozzle throat diameter were kept constant during the test series. As Fig. 6 shows $c^{*}$ increases with increasing chamber pressure. Furthermore the difference between the theoretical and experimental $c^{*}$ decreases with increasing chamber pressure. Thus the combustion efficiency $\eta_{\mathrm{c}^{*}}$ grows with increasing chamber pressure. The cause of the increase in combustion efficiency with rising chamber pressure is most likely that proportionally less heat is lost to the chamber walls at higher chamber pressures [34, 37]. 


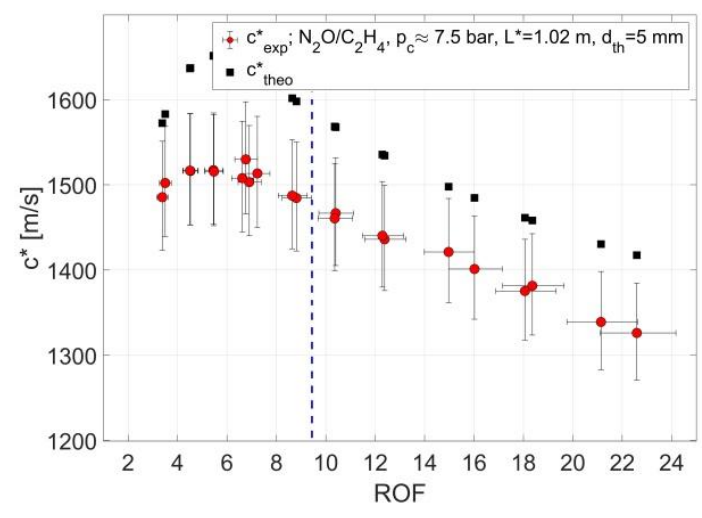

Fig. 5: Experimental and theoretical $c *$ of $\mathrm{N}_{2} \mathrm{O} / \mathrm{C}_{2} \mathrm{H}_{4}$ propellant depending on mixture ratio [37]

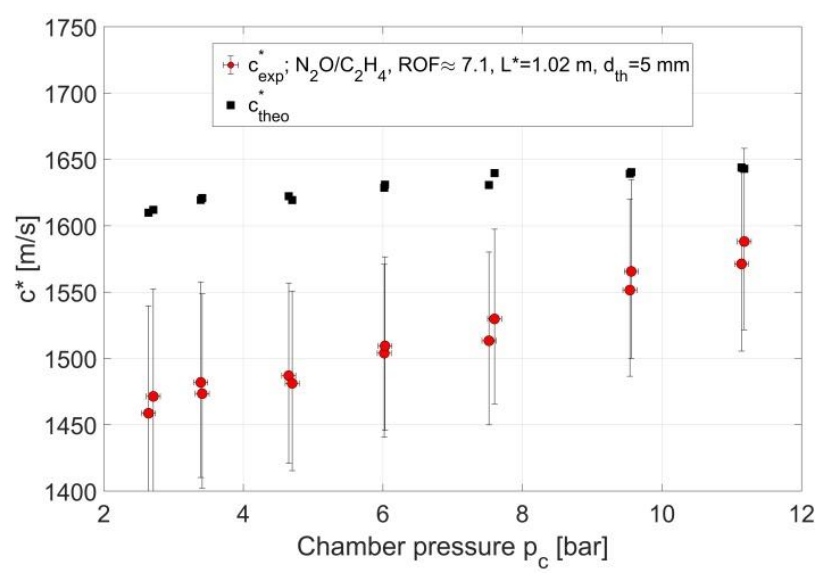

Fig. 6: Experimental and theoretical c* of $\mathrm{N}_{2} \mathrm{O} / \mathrm{C}_{2} \mathrm{H}_{4}$ propellant depending on chamber pressure

2. Heat loads on combustion chamber walls

During several test campaigns not only the combustion efficiency but also the heat loads on the chamber walls were studied [34, 37]. Fig. 7 and Fig. 8 give the experimentally derived heat loads (red triangles) of a $\mathrm{N}_{2} \mathrm{O} / \mathrm{C}_{2} \mathrm{H}_{4}$ propellant and compare the results to four different Nusselt Number correlations. For the test series given in Fig. 7, the chamber pressure, the chamber length and the nozzle throat diameter were again kept constant. As Fig. 7 shows, the highest experimental heat fluxes are obtained at near stoichiometric mixture ratios $(\mathrm{ROF}=9.41)$. The comparison of the Nusselt-correlations shows that for lean and rich mixture ratios (ROF $\leq 5$ and $\mathrm{ROF} \geq 13$ ) the Bartz-equation predicts the heat flux quite well. For mixture ratios in between ROF $>5$ and ROF $<11$ the equations according to Gnielinski or Cinjarew correlated quite well with the experimental data [37].

Fig. 8 shows the experimental and calculated heat fluxes on the combustion chamber walls depending on the chamber pressure. Here the mixture ratio, chamber length and nozzle throat diameter was kept constant. According to the measurement data in Fig. 8, the Nusselt-correlation of Cinjarew gives the most accurate prediction of the occurring heat loads.

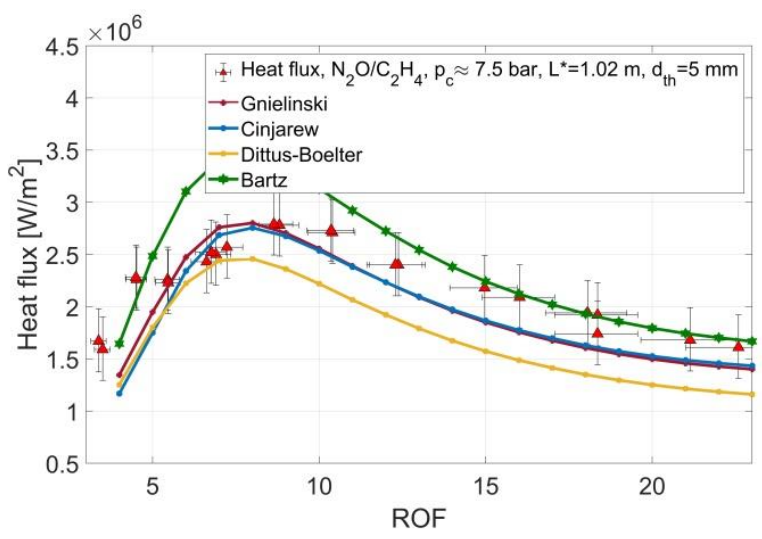

Fig. 7: Experimental and calculated heat flux depending on mixture ratio [37]

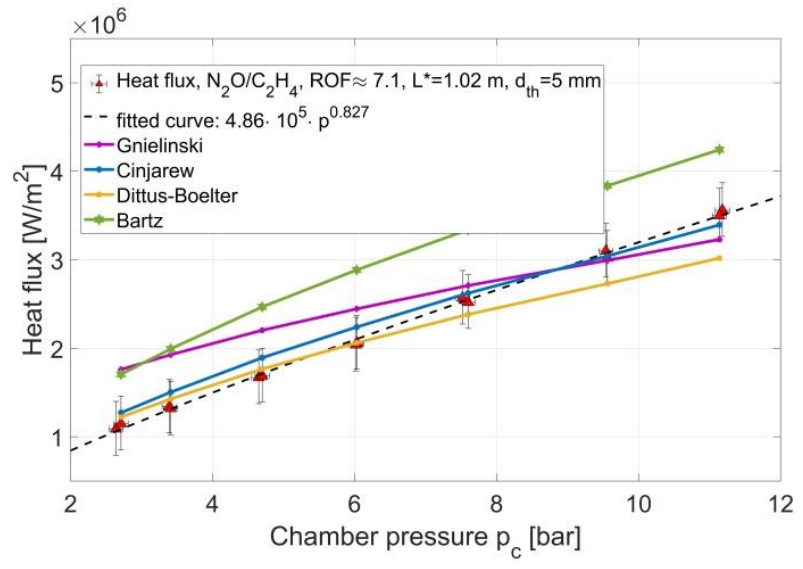

Fig. 8: Experimental and calculated heat flux depending on chamber pressure [37]

\section{Testing of flashback arresters in the experimental combustion chambers}

As initially mentioned, suitable flashback arresters in the injection and propulsion system are needed to avoid flame propagation from the combustion chamber to the feeding lines and tank structure. As numerous combustion tests showed, during ignition a flame flashback is very likely if no flame arrester is mounted. To test and evaluate different flame arresters, a specific setup (ignition test section, see Fig. 15) was used. In parallel to the experiments 
conducted in the ignition test section, different flame arresters were tested in the rocket combustor. Due to small pore sizes, good availability and low cost, sintered porous materials were selected as suitable flame arresters.

Fig. 9 and Fig. 10 show two of the used porous materials. Both sintered bronze materials and sintered stainless steel materials were used as flame arresters. Due to their high heat conductivity and lower pressure drop the sintered bronze turned out to be more suitable as flashback arrester. To reliably prevent a flashback during ignition, steady state operation and shut down of the combustor, pore sizes smaller than $50 \mu \mathrm{m}$ are necessary for the gaseous $\mathrm{N}_{2} \mathrm{O} / \mathrm{C}_{2} \mathrm{H}_{4}$ propellant. For the gaseous $\mathrm{N}_{2} \mathrm{O} / \mathrm{C}_{2} \mathrm{H}_{6}$ mixture pore sizes smaller than $70 \mu \mathrm{m}$ are recommended.

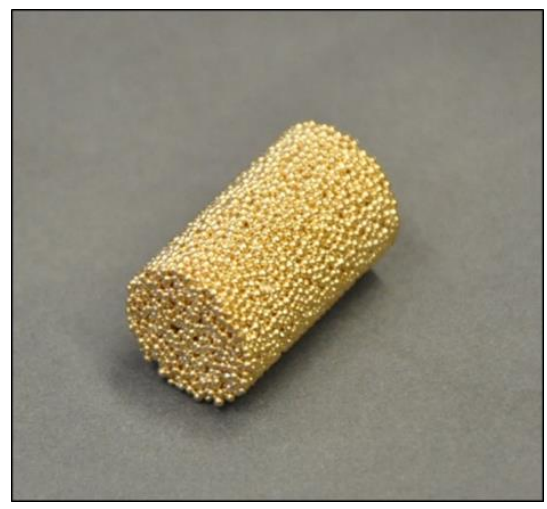

Fig. 9: Sintered bronze porous material

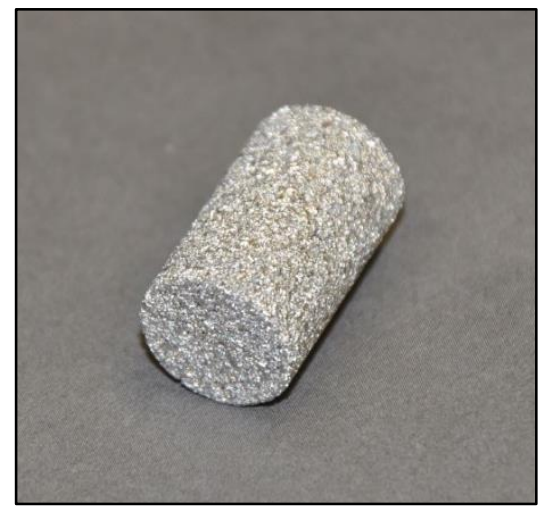

Fig. 10: Sintered stainless steel porous material

\section{Investigations of regenerative cooling}

Due to the high combustion temperatures (around $3000 \mathrm{~K}$ ) of the $\mathrm{N}_{2} \mathrm{O} / \mathrm{C}_{2} \mathrm{H}_{4}$ and $\mathrm{N}_{2} \mathrm{O} / \mathrm{C}_{2} \mathrm{H}_{6}$ mixtures, a sufficient cooling for the combustion chamber and nozzle must be provided. Since conventional materials cannot withstand the high combustion temperatures and film cooling is not applicable due to the premixed state of the propellant, the possibility of regenerative cooling was investigated. To cool the chamber walls, a further development of the combustor included cooling channels in one chamber segment.

Fig. 11 shows the glowing combustion chamber during a steady state hot run. In comparison Fig. 12 gives the temperature development for different positions at the chamber walls and for the nozzle during a 5 minute hot run of the combustor. Although wall temperatures of up to $900^{\circ} \mathrm{C}$ occurred during the test campaign, no ignition of the propellant inside the cooling channels was observed. Most likely the residence time of the propellant inside the cooling channels was too short to allow an ignition. In case of the $\mathrm{N}_{2} \mathrm{O} / \mathrm{C}_{2} \mathrm{H}_{4}$ propellant soot and coking in the cooling channels was observed. For the $\mathrm{N}_{2} \mathrm{O} / \mathrm{C}_{2} \mathrm{H}_{6}$ propellant no coking was observed during the hot runs. The tests showed that regenerative cooling allows steady state operation of the combustor for various operating points even for the gaseous, premixed propellant and for low mass flows.

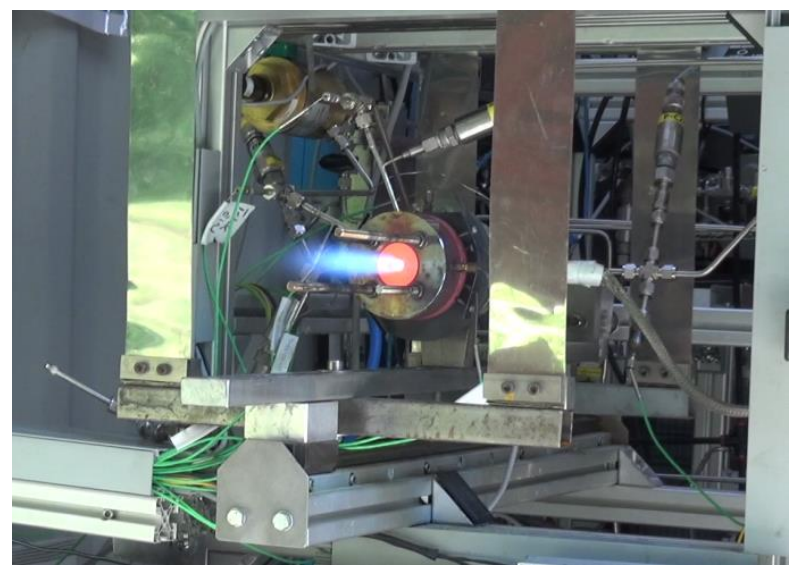

Fig. 11: Regenerative cooled combustion chamber during hot run

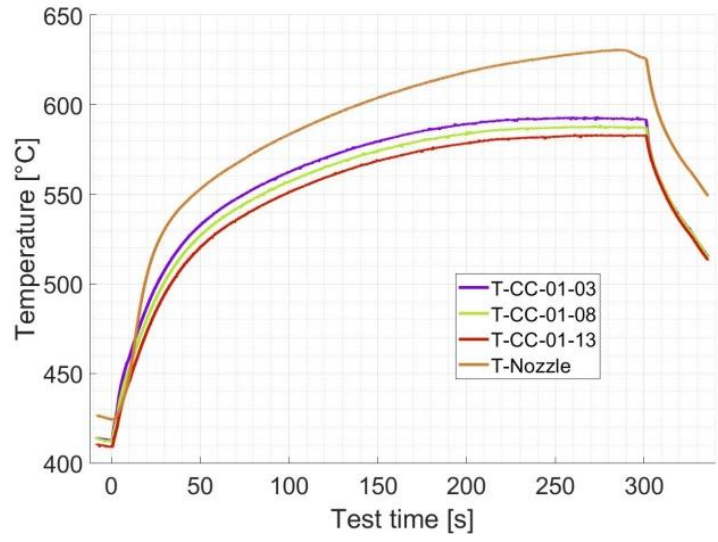

Fig. 12: Temperatures at different positions during hot run of regenerative cooled chamber 


\section{Tests with liquefied propellants}

In addition to the test with gaseous propellant, liquefied $\mathrm{N}_{2} \mathrm{O} / \mathrm{C}_{2} \mathrm{H}_{4}$ and $\mathrm{N}_{2} \mathrm{O} / \mathrm{C}_{2} \mathrm{H}_{6}$ propellants were used during combustion tests. Fig. 13 shows a cold flow test of the injector with liquefied $\mathrm{N}_{2} \mathrm{O} / \mathrm{C}_{2} \mathrm{H}_{4}$. Due to the high vapor pressure, the propellant flash evaporates when exposed to ambient conditions.

Fig. 14 gives the chamber pressure during a hot run with liquefied $\mathrm{N}_{2} \mathrm{O} / \mathrm{C}_{2} \mathrm{H}_{4}$. In contrast to the tests with gaseous propellant, significantly higher pressure fluctuations (more than $10 \%$ of the average pressure) were observed. Those increased fluctuations are most likely caused by the evaporation processes of the propellant. Furthermore when a flashback occurred during operation with the liquefied propellant, the increased mass of combustible propellant in the feeding lines caused the destruction of the $6 \mathrm{~mm}$ feeding tube.

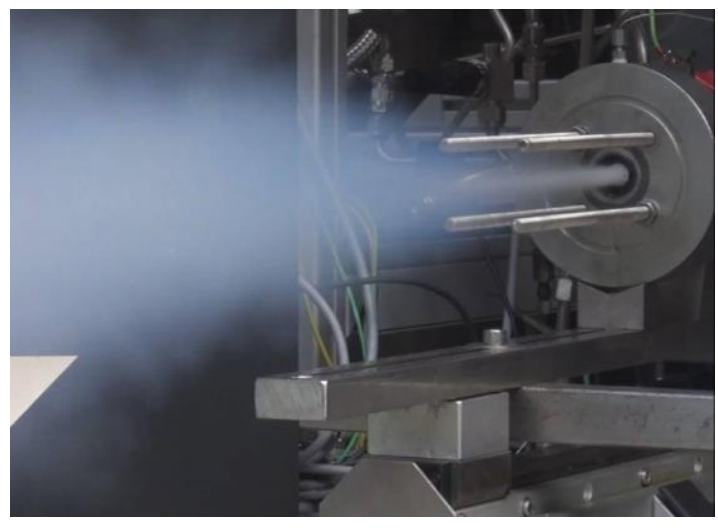

Fig. 13: Injector cold flow with liquefied $\mathrm{N}_{2} \mathrm{O} / \mathrm{C}_{2} \mathrm{H}_{4}$

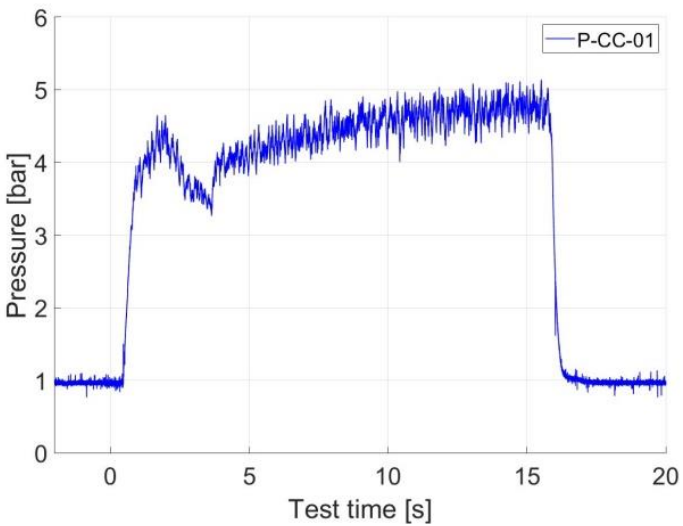

Fig. 14: Chamber pressure during $15 \mathrm{~s}$ combustion test with liquefied $\mathrm{N}_{2} \mathrm{O} / \mathrm{C}_{2} \mathrm{H}_{4}$

\section{B. Investigations of the flame propagation processes and evaluation of flame arresters}

To investigate the flame propagation process and to evaluate various flame arresters, a so called ignition test section was built. The test section allows the investigation of porous flame arresters with different lengths and pore sizes. In addition to the experiments with porous materials, quenching experiments with small tubes (capillaries) were conducted to compare the quenching behavior of tubes and porous materials.

The test section consists of two chambers which are separated by the flame arrester. Both chambers are equipped with windows that allow high speed imaging of the flame propagation process. Furthermore pressure and temperature sensors are mounted at both chambers to investigate the pressure and temperature rise during the flame propagation and during flame flashback. The gaseous propellant mixture can be ignited in either of the chambers via spark plug. The test chambers were filled with gaseous propellant which was mixed in a separate vessel by using the partial pressure of $\mathrm{N}_{2} \mathrm{O}$ and $\mathrm{C}_{2} \mathrm{H}_{4}$. Prior to each ignition tests, the chambers were evacuated by vacuum pump and then filled with gaseous propellant to the required pressure. After each combustion test the chambers were evacuated again. Most of the ignition experiments were performed with stoichiometric $\mathrm{N}_{2} \mathrm{O} / \mathrm{C}_{2} \mathrm{H}_{4}$ compositions, because near the stoichiometric mixture ratio the combustion temperatures and flame speeds are at their maximum values. Fig. 15 shows a sectional view of the ignition test section. 


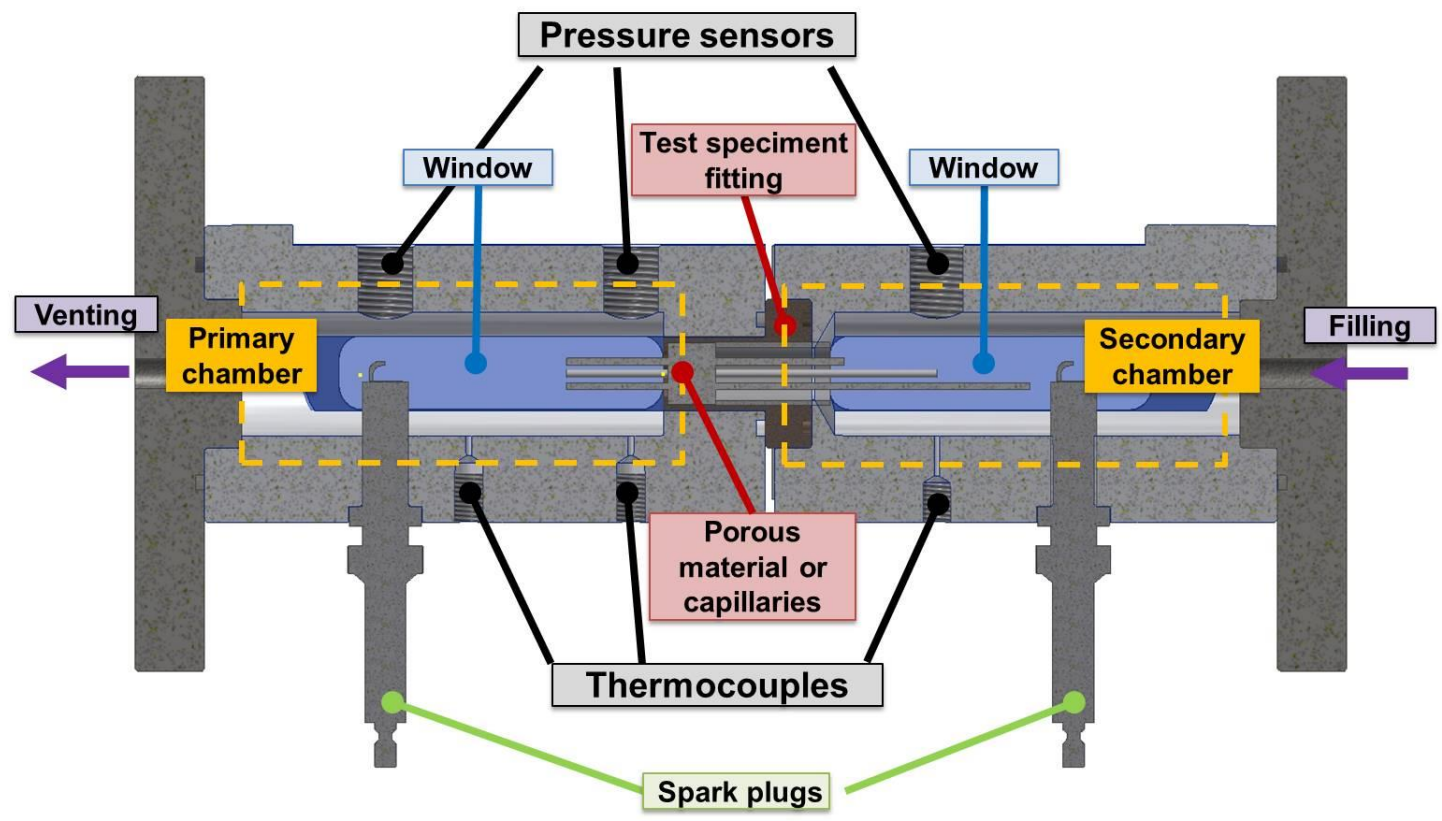

Fig. 15: Ignition test section for investigation of flame arresters (porous materials and capillaries)

Fig. 16 shows a series of high speed images during the flame propagation inside the ignition test section. Here the ignition was triggered at the spark plug in the secondary chamber. Initially the flame propagates laminar and spherically starting from the point of ignition (image 1 and 2 in Fig. 16). In the course of the flame propagation, the geometry of the test chambers causes a "finger-shaped" laminar flame (image 3 and 4 in Fig. 16). With increasing initial pressure, the formation of instabilities at the laminar flame front is amplified. These instabilities increase the surface of the flame front and thus accelerate the flame. Therefore with increasing pressure prior to ignition the average flame propagation speed rises [40, 41].

In between image 4 and 5 of Fig. 16 the flame reaches the flame arrester. If the pores or channels of the flame barrier are not able to quench the flame, the flame passes and propagates inside the downstream chamber. Due to the flow conditions the turbulence in the downstream chamber is strongly increased, thus the flame spreads as turbulent flame after passing the flame arrester (image 5-7 of Fig. 16). Depending on the boundary conditions as e.g. the initial pressure, the flow path and the turbulence, the formation of very fast flames with speeds in the range of the theoretical detonation velocity were observed. This agrees well with investigations of Venkatesh et al. [42, 43] who showed that $\mathrm{N}_{2} \mathrm{O} / \mathrm{C}_{2} \mathrm{H}_{4}$ mixtures can quickly form detonations. 


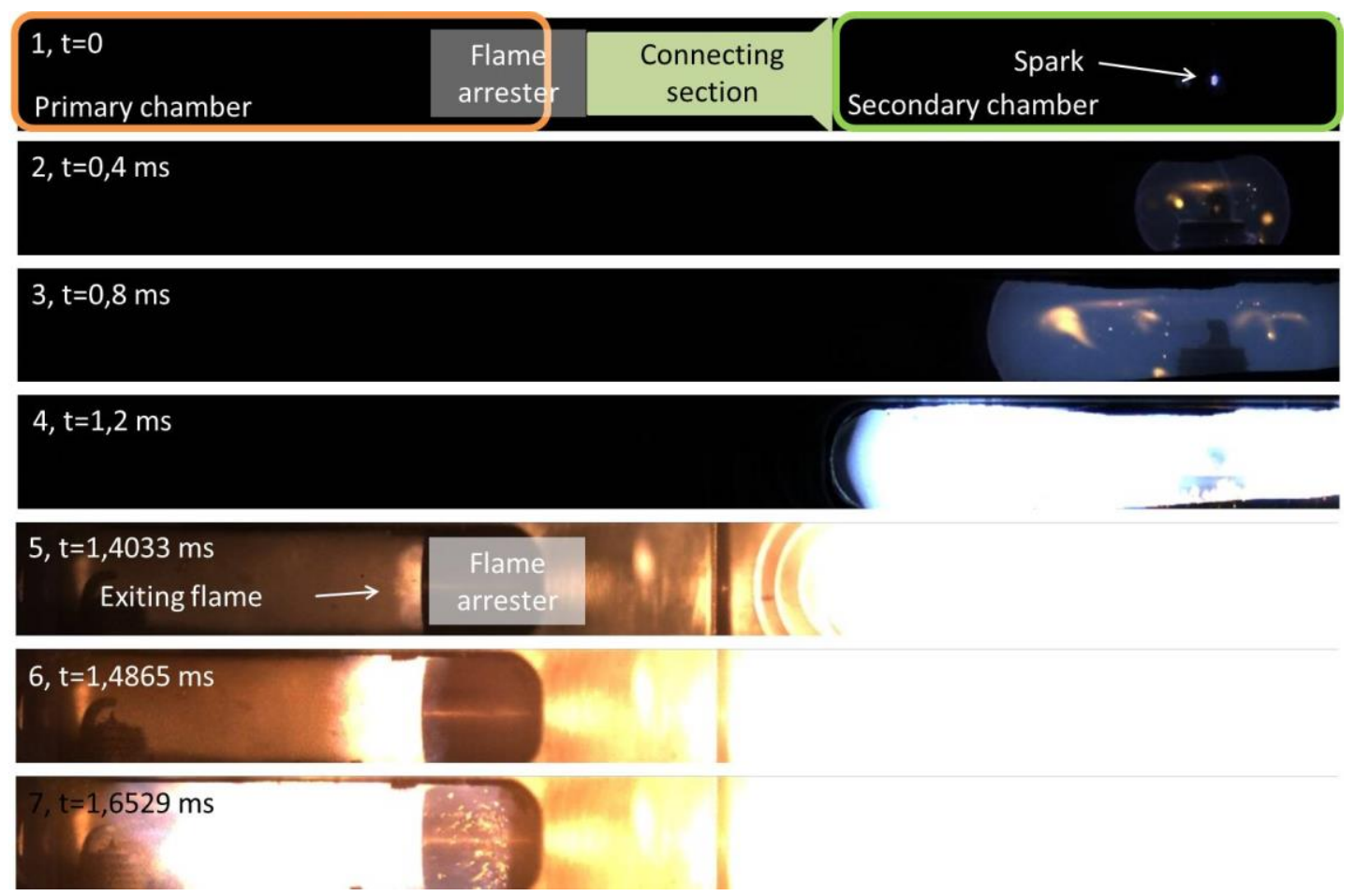

Fig. 16: High Speed Images of $\mathrm{N}_{2} \mathrm{O} / \mathrm{C}_{2} \mathrm{H}_{4}$ flame propagation mechanism, ignition at spark plug in secondary chamber

The expansion of the hot combusted gases behind the flame front cause a flow across the flame arrester. Due to the flow resistance of the porous material or capillaries and the pressure increase caused by the hot combustion products in the closed volume, a pressure gradient across the flame barrier is formed. Fig. 17 gives the assumed pressure gradient across the flame arrester when the ignition is triggered in the first chamber and the flame enters the flame arrester. According to flame quenching theory [44-47] a higher density and thus pressure of the unburned mixture leads to a reduced quenching diameter, while a lower pressure and density cause an increase of the quenching diameter. If the pores or channels of the flame barrier are small enough or the pressure drop across the flame arrester is large enough, the flame will be quenched after a certain distance (marked as red line in Fig. 17). Aside with the calculation of quenching Péclet-numbers (see e.g. [44, 45, 48, 49]) the relationship in between the pressure drop of the porous materials and the occurrence of flame flashback was investigated in detail. Due to the closed geometry of the test chambers and the position of the flame arrester, it was assumed that the pressure inside the chamber during contact of the flame with the flame arrester corresponds to the maximum explosion pressure (see [50] for definition) of the given mixture.

Fig. 18 shows the pressure drop of the porous material and the corresponding explosion pressure for several ignition and flashback tests. The diagram gives the largest calculated explosion pressure and related pressure drop for tests in which no flashback did occur (green triangles) as well as the lowest calculated explosion pressure and pressure loss in which a flashback was observed (red triangles). The pressure drop of the porous materials was calculated according to the Forchheimer equation [51] for the corresponding state of the unburned gas (density, viscosity), the permeability coefficients and length of the porous material as well as a reference Darcy-velocity of 1 $\mathrm{m} / \mathrm{s}$. After inserting the data points a boundary line can be drawn, below which no flame flashback was observed (light blue, dashed line). To avoid flame flashback, the flame arrester should ensure a sufficient pressure drop and the explosion pressure should be low enough to result in values below the light blue, dashed line in Fig. 18. 


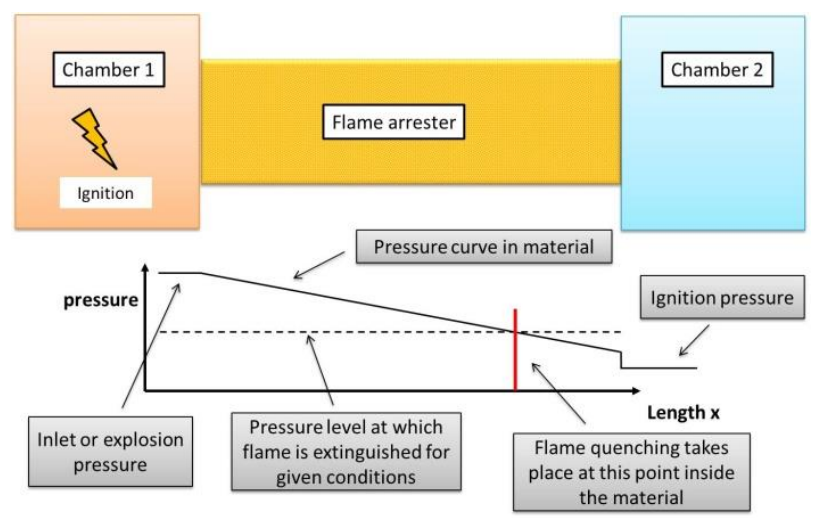

Fig. 17: Pressure drop inside the porous material when flame enters

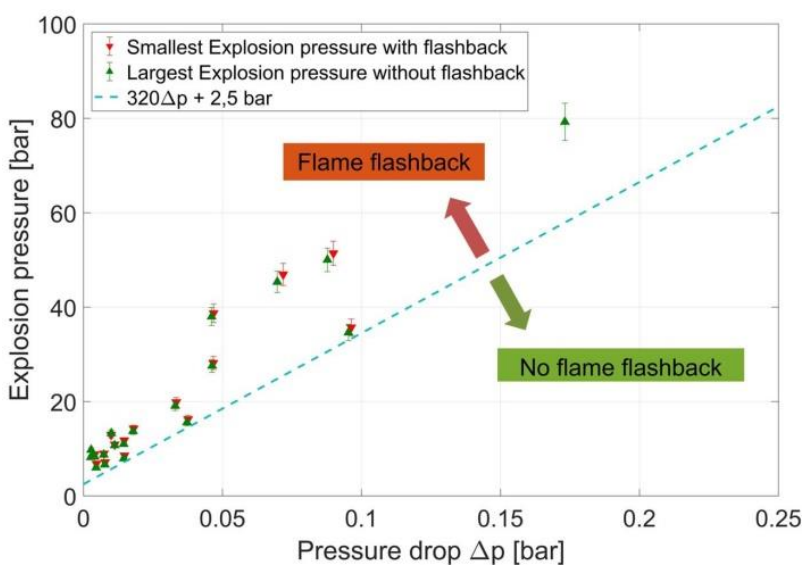

Fig. 18: Maximum explosion pressure to avoid flame flashback depending on pressure drop of porous material

\section{Research on combustion behavior (laminar flame speed and reaction mechanisms)}

To enable and to support computational fluid dynamics (CFD) simulations reaction mechanisms were developed, optimized and validated at in-house measurements of ignition delay times and laminar flame speeds of ethene/nitrous oxide and ethane/nitrous oxide mixtures at several conditions.

\section{Ignition delay time experiments}

Ignition delay time measurements were done at DLR's shock tube facility in Stuttgart, Germany [52, 53]. The shock tube has an inner diameter of $9.82 \mathrm{~cm}$ and its length is divided by aluminum diaphragms into a driver section of $5.18 \mathrm{~m}$ and a driven section of $11.12 \mathrm{~m}$. Driver and driven sections are separated by a small intermediate volume enabling a double-diaphragm operation. The pressure in the driven section was reduced below $10^{-6}$ mbar by a turbomolecular pump, before prepared reactive hydrocarbon / nitrous oxide gas mixtures were filled in. They were prepared before in stainless steel storage cylinders, which were evacuated using another turbomolecular pump and then filled with manometric determined amounts of gas from Linde AG with the following purities: $\mathrm{N}_{2} \mathrm{O}: 99.999 \%$, $\mathrm{C}_{2} \mathrm{H}_{6}: 99.95 \%, \mathrm{C}_{2} \mathrm{H}_{4}: 99.95 \%$, diluent $\mathrm{N}_{2}: 99.9995 \%$. Mixtures containing nitrous oxide as oxidant have a very short deflagration-to-detonation time. To avoid detonations inside shock tube and to reduce dynamic load to the shock tube during ignition and deflagration were only reaction mixtures of hydrocarbons and nitrous oxide diluted 1:5 with nitrogen investigated. These reaction mixtures were heated up first by a shockwave generated through rupture of aluminum diaphragms by inert gas mixtures at higher pressure in the driver section and heated up again by the reflected shock wave, which results from reflection of incident shockwave at endplate of the shock tube. To extend observation time to about $8 \mathrm{~ms}$ tailoring was used. Mixture composition and pressure of monoatomic inert gases helium and argon in driver section were controlled by mass flow controllers to achieve tailored interface conditions. They are reached when no unsteady wave disturbance propagates into the shock tube gas mixture as a result of interaction of reflected shock wave and driver gas interface; resulting in a rest of the interface through the reflected shock wave and therefore resulting in a prolongation of observation time. Resulting post-shock compression has to be taken into account during interpretation and modelling of data. Due to this post-shock pressure rise at longer observation periods, i.e. at lower initial temperatures, ignition delay times tend to become shorter due to increasing temperature induced by post shock pressure increase, especially at elevated initial pressures. Four piezoelectric pressure gauges (PCB 113B24) with $200 \mathrm{~mm}$ distance between each other were used for determination of speed of the shockwaves. They were shielded by polymers to reduce heat transfer and therefore drift of the detected signals. Temperature and pressure behind reflected shockwave were computed from measured speed of incident shock wave and its speed attenuation using a one-dimensional shock model. Within these measurements uncertainty in reflected shock temperature is estimated to be less than $\pm 15 \mathrm{~K}$, which was derived from carbon monoxide absorption/emission measurements.

Ignition delay times were measured behind reflected shock waves at initial pressures of a nominal pressure of 1 , 4 , and 16 bar. All ignition delay time values were determined by measuring the time difference between initiation of the reactive system by reflected shock wave at the end plate of the shock tube and occurrence of first maximum of emission of $\mathrm{CH}(\mathrm{A})$ at $431 \mathrm{~nm}$ at side port and alternatively through end plate window. 


\section{Laminar Flame Speed Experiments}

Laminar flame speeds of preheated hydrocarbon/nitrous oxide gas mixtures diluted 1:2 with nitrogen were measured in a high pressure burner system [53, 54]. This setup consists of a flow controlling system for fuel, oxidizer, diluent, an ignition system, flame holder, burner housing with pressure control system and an exhaust gas heat exchanger. Gases from Linde $\mathrm{AG}\left(\mathrm{N}_{2} \mathrm{O}: 99.95 \%, \mathrm{C}_{2} \mathrm{H}_{4}\right.$ : $99.95 \%, \mathrm{C}_{2} \mathrm{H}_{6}$ : $99.95 \%$, diluent $\mathrm{N}_{2}$ : $\left.99.999 \%\right)$ were used and its mass flow controlled by calibrated equipment from Bronkhorst. The copper made flame holder is heated to $473 \mathrm{~K}$ and the bulk and gas temperature were monitored by K-type thermocouples. To stabilize the flame and measure its laminar flame speed at different equivalence ratios and pressures contracting nozzles of different outlet diameters $(1.5$ to $8.0 \mathrm{~mm})$ were necessary. Usually, one change in nozzle diameter was sufficient to cover the complete range of fuel equivalence ratios at one pressure. From the stabilized flames magnified digital images were taken by a combination of a telecentric zoom lens (Navitar, 12x) and a CCD camera (La Vision, Imager pro). Within the flame front, a thin region of high temperature, the chemiluminescence, which is the emission of light from radicals, such as $\mathrm{CH}$ and $\mathrm{OH}$, which were chemically and/or thermally excited and were returning to their ground state, is very strong and is analyzed by an edge detection algorithm to calculate the flame contours and cone angles necessary for calculation of laminar flame speeds. The laminar flame speed is influenced by the reactivity and heat release of the investigated mixtures as well as their diffusivity and provides important information for construction and design of technical combustion systems. It gives information how prone the flame is to instabilities such as flashback or blow off, which will be considered by calculation of quenching diameters necessary for the construction of flashback arresters.

Therefore these investigations are providing important results for enhancing the safety by handling and use of hydrocarbon / nitrous oxide blends.

\section{Chemical kinetic modeling}

For the chemical kinetic modeling approach of the nitrous oxide and hydrocarbon mixtures the chemical kinetic model GRI3.0 [55] was adapted and optimized [53]. Furthermore, the optimized model was reduced with the methods of the linear transformation model (linTM) [56] to allow the efficient application in computational fluid dynamics (CFD).

The main adaptation by Naumann et al. [53] of the chemical kinetic model GRI3.0 was the integration of the reactions proposed by Powell et al. [57] as well as the addition of high temperature dissociation reactions of $\mathrm{N}_{2}$, NO and $\mathrm{CO}$ and a submodel for the required chemiluminescence reactions [58]. Additionally, the factors for the collision efficiencies were adapted [53].

In a next step an optimization of the chemical kinetic model on the experimental data was performed by utilizing the linTM [56]. With the optimization five sensitive reaction rates were adjusted within their uncertainties [53]. Thereby, the following reactions were optimized:

$$
\begin{aligned}
& \mathrm{N}_{2} \mathrm{O}\left(+\mathrm{N}_{2}\right) \leftrightarrow \mathrm{N}_{2}+\mathrm{O}\left(+\mathrm{N}_{2}\right) \\
& \mathrm{N}_{2} \mathrm{O}+\mathrm{H} \leftrightarrow \mathrm{N}_{2}+\mathrm{OH} \\
& \mathrm{N}_{2} \mathrm{O}+\mathrm{H} \leftrightarrow \mathrm{NH}+\mathrm{NO} \\
& \mathrm{H}+\mathrm{NO}+\mathrm{M} \leftrightarrow \mathrm{HNO}+\mathrm{M} \\
& \mathrm{HNO}+\mathrm{H} \leftrightarrow \mathrm{H}_{2}+\mathrm{NO}
\end{aligned}
$$

Subsequently, the optimized model was reduced with the method of the rapid reduction of the linTM [56]. With this method an initial target set of species profiles in homogeneous, adiabatic, isobaric reactors and laminar flame speed profiles was generated with the optimized model. The highly automated reduction process consists of two major steps. First, a species reduction based on a sensitivity analysis is conducted with the linTM for the species and flame speed profiles of the initial target set [56]. In the second step, the species and flame speed profiles produced by the reduced chemical kinetic model are post-optimized on the initial target set with the linTM. In general, this procedure allows a strong reduction grade of chemical kinetic models while simultaneously keeping a high prediction capability compared to the initial detailed model.

The boundary conditions for the initial target set for the rapid reduction were designed to meet the conditions in the combustion experiments and the ignition and flashback tests. The species profiles were simulated for ethene nitrous oxide mixtures at initial temperatures of $1300 \mathrm{~K}, 1600 \mathrm{~K}, 2000 \mathrm{~K}$ and $2400 \mathrm{~K}$, at pressures of $1 \mathrm{bar}, 3 \mathrm{bar}$ and $10 \mathrm{bar}$, with the fuel-oxidizer equivalence ratios $\varphi$ of $0.5,1.0$ and 1.5. Species were targeted that reached at least a mole fraction of $1 \%$ during the reaction process under the given boundary conditions. Two laminar flame speed 
profiles were targeted for the reduction process within this work. The initial temperature for the flame speed simulation of the ethene nitrous oxide mixture was $298 \mathrm{~K}$ and the pressures were $1 \mathrm{bar}$ and $10 \mathrm{bar}$.

All chemical kinetic simulations were conducted with the open source software Cantera [59].

\section{Chemical kinetic results}

Fig. 19 and Fig. 20 depict the experimental as well as the chemical kinetic modelling results for the combustion investigation of the ethene nitrous oxide mixtures from Naumann et al. [53]. With the adaptations of the model GRI 3.0 the deviations of the chemical kinetic model predictions and the experimental results for both ignition delay times and laminar burning velocities were significantly reduced. Eventually, with the optimization a chemical kinetic model was generated that is consistently in excellent agreement with all experimental data in Fig. 19 and Fig.

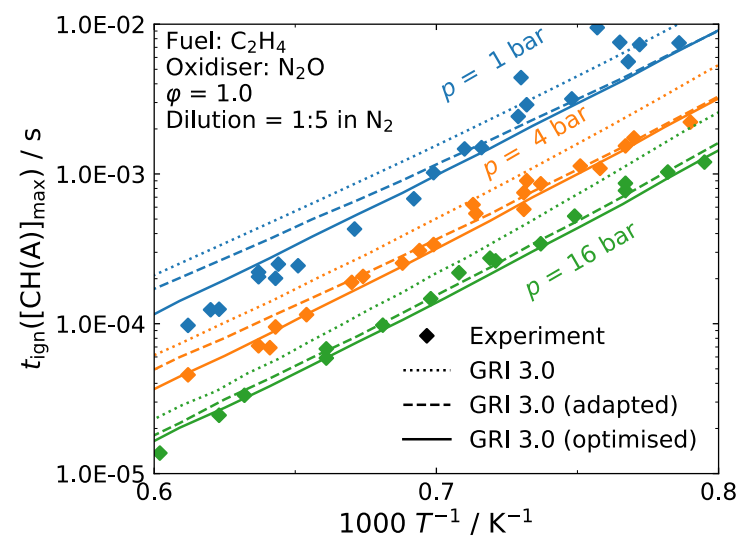

Fig. 19: Experimental and numerical results for ignition delay times of ethene/nitrous oxide mixtures with experimental data from Naumann et al. [53]

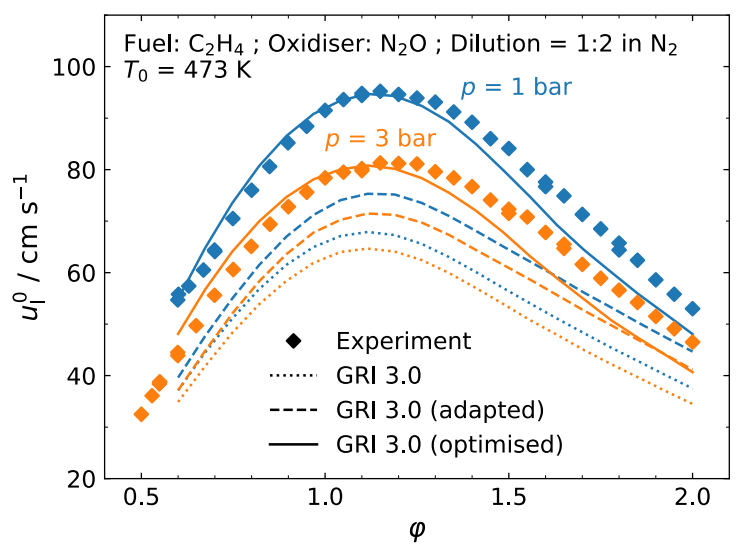

Fig. 20: Laminar burning velocities of ethene/nitrous oxide mixtures with experimental data from Naumann et al. [53]

20.

With the reduction of the optimized chemical kinetic model, the number of species was significantly reduced from 56 to 22. Fig. 21, Fig. 22, Fig. 23 and Fig. 24 compare the exemplary results from the different models of targeted laminar flame speed profiles, species profiles and ignitions delay times - which were indirectly targeted by the major species profiles of the homogeneous reactors. The reduced chemical kinetic model with 22 species shows significant deviations compared to the detailed model GRI 3.0 (optimised).

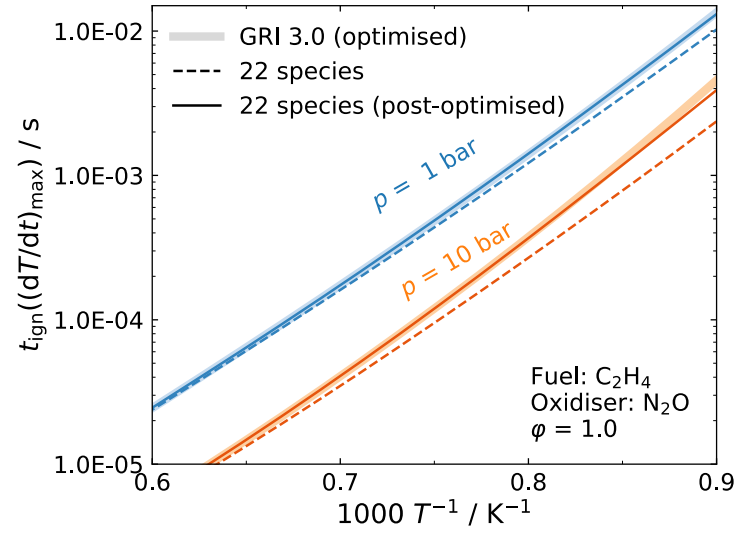

Fig. 21: Numerical performance of the reduced chemical kinetic models against the detailed model for targeted ignition delay times

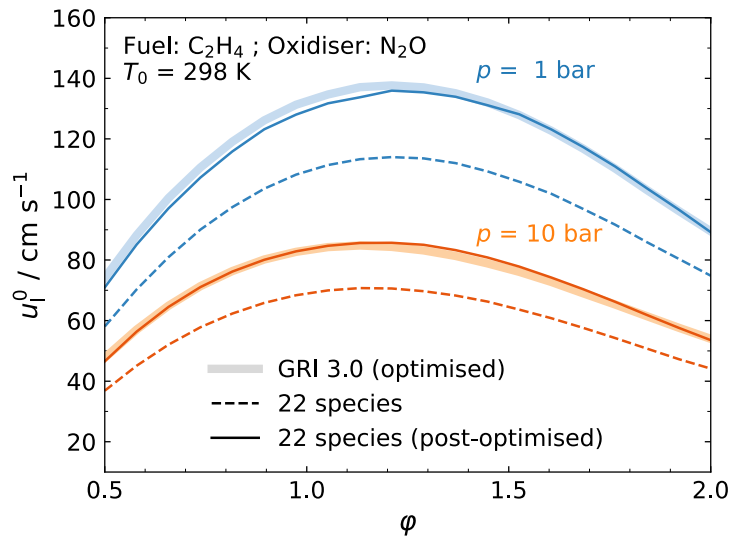

Fig. 22: Numerical performance of the reduced chemical kinetic models against the detailed model for targeted laminar flame speeds 
Contrary, the successfully post-optimized 22 species model is almost in perfect agreement with the detailed model. Thus, with this validation of the reduced model with the detailed model, the post-optimized model is fully eligible for the application in the intended CFD simulations within this work.

\begin{tabular}{|l|l|l|l|l|}
\hline &
\end{tabular}

\section{Numerical simulations of flame propagation mechanism}

To gain additional knowledge of the ongoing processes during the ignition, combustion and flashback experiments, numerical simulations of the combustion process were conducted. The simulations were carried out by using the post-optimized reaction mechanism with 22 species described in the last section within the commercial CFD Software ANSYS Fluent. In transient simulations the ignition test section was modelled as 2-dimensional axisymmetric domain while the k- $\omega$-SST turbulence model was used. Preliminary investigations showed a sufficient resolution of the flame propagation process for time steps of $40 \mu \mathrm{s}$ while using a structured mesh of $125 \times 50 \mu \mathrm{m}$ grid width. The mesh's resolution was increased towards the walls and inside the capillary to resolve the boundary layers correctly.

Fig. 25 gives a comparison between an experiment and a simulation with identical boundary conditions (initial temperature $=300 \mathrm{~K}$, initial pressure $=0.675 \mathrm{bar}$, mass related mixture ratio $=9.41$ ). The black and white highspeed images of the experiments are shown in the top of each single image in Fig. 25, below the results of the simulation are shown. The colors in the images of the simulation indicate the temperature inside the test chamber from blue (low temperature) to red (high temperature). As Fig. 25 shows, the shape and propagation mechanisms of the flame are reproduced quite well. However, there are differences in between the experimentally observed and simulated flame propagation speeds. The simulated flame velocity is up to $30 \%$ slower than the speed of the experimental flame. These deviations are most likely caused by differences in the geometry of the simulated domain and the experimental test section. In contrast to the simulated domain, the experimental test chambers are not perfectly cylindrical (vertical walls at both sides where the windows are located). Furthermore small variations of the calculated laminar flame speed and probably a non-sufficient grid or time step resolution may cause the deviations in the flame propagation velocities.

In addition to the investigations of the flame propagation, the flashback processes were simulated. Fig. 25 shows an experiment and simulation with a capillary as flame arrester. As the simulation shows, the flame accelerates strongly after entering the capillary due to the pressure difference in between the primary and secondary chamber. Caused by the high velocities, the flame is strongly stretched inside the capillary.

Following the simulations of the flame propagation processes inside the ignition test section, simulations of the rocket combustor are planned. Those simulations should allow the comparison of the numerically derived performance parameters $\left(\mathrm{c}^{*}, \eta_{\mathrm{c}^{*}}\right)$ and heat fluxes to the experimental results. 

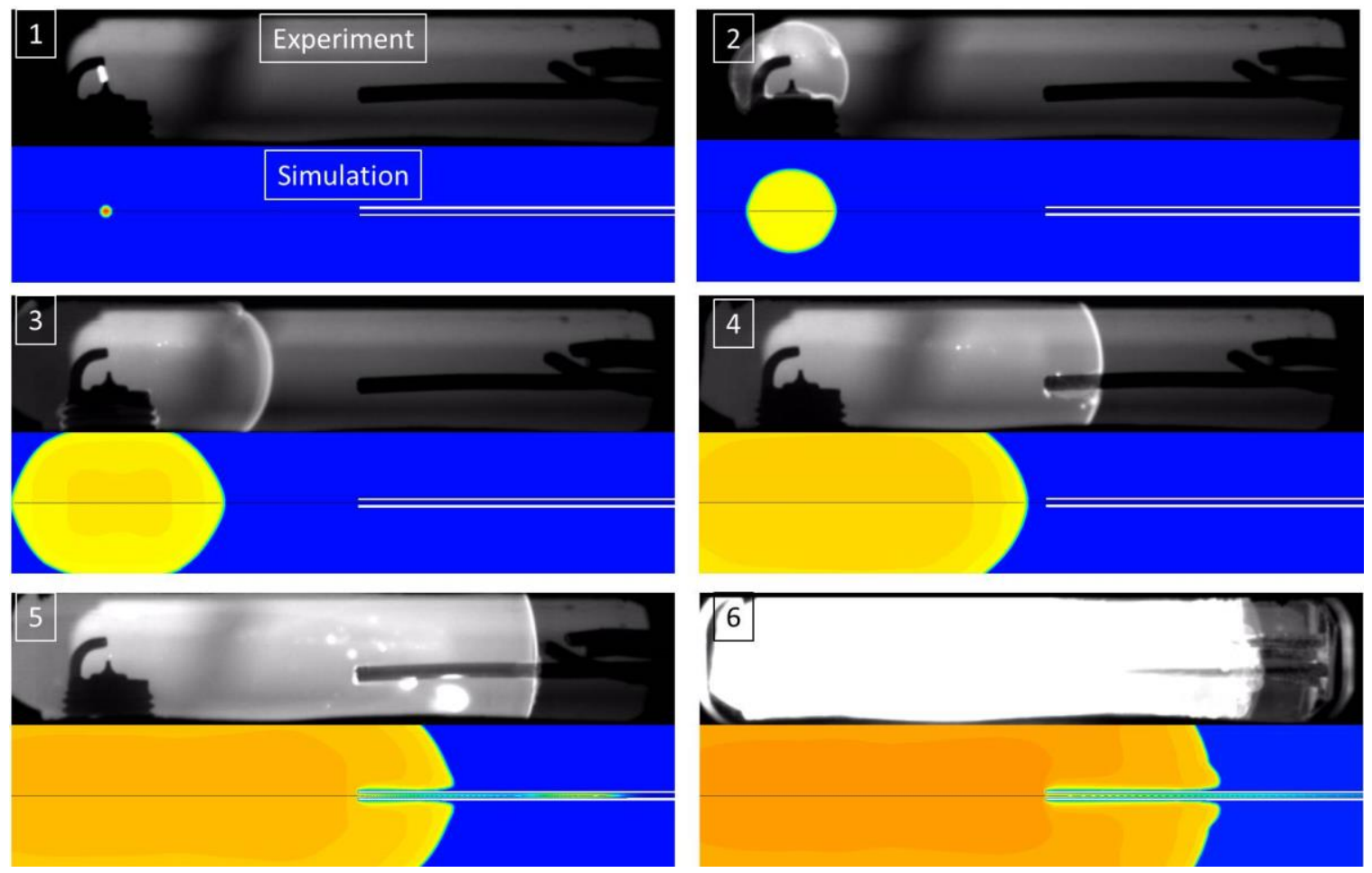

Fig. 25: High speed images of ignition and flashback experiments and corresponding CFD simulation (capillaries used as flashback arresters, colors in simulation indicate temperature levels)

\section{E. Investigations of propellant miscibility}

In a later propulsion system the liquid $\mathrm{N}_{2} \mathrm{O} / \mathrm{C}_{2} \mathrm{H}_{4}$ or $\mathrm{N}_{2} \mathrm{O} / \mathrm{C}_{2} \mathrm{H}_{6}$ propellant is intended to be stored in one tank. Thus the investigation of the propellant miscibility and storability is essential. The propellant should form a homogeneous mixture or solution and during the lifetime of a space craft the single components should not de-mix or separate. If the propellant does not mix properly, performance losses or even injection of non-combustible mixture into the combustion chamber is possible.

To assess the propellant miscibility, a mixing setup was built. The setup allows mixing of liquefied $\mathrm{N}_{2} \mathrm{O}$ and $\mathrm{C}_{2} \mathrm{H}_{6}$ at ambient temperatures for pressure levels up to 70 bar. To adjust and determine the mixture ratio, the setup is equipped with transparent polycarbonate tubes which allow visual observation of the liquid and gaseous $\mathrm{N}_{2} \mathrm{O}$ and $\mathrm{C}_{2} \mathrm{H}_{6}$ prior and after mixing. Via temperature and pressure sensors the state of the gases and liquids before and after mixing is monitored. First investigations showed a homogeneous mixture of the liquid $\mathrm{N}_{2} \mathrm{O}$ and $\mathrm{C}_{2} \mathrm{H}_{6}$ while no phase separation was visible. However due to limitations of the setup so far only mass related mixture ratios of ROF $=1-3$ were tested, which are too rich to be used as propellant. Fig. 26 shows liquefied and mixed $\mathrm{N}_{2} \mathrm{O} / \mathrm{C}_{2} \mathrm{H}_{6}$ propellant at a mass mixture ratio of about $\mathrm{ROF}=1$ in the transparent tubes of the mixing setup.

The miscibility investigations will be continued in the framework of the ESA project "High Performance Propellant Development". Furthermore the propellant compatibility with typical aerospace materials will be examined within this activity. 


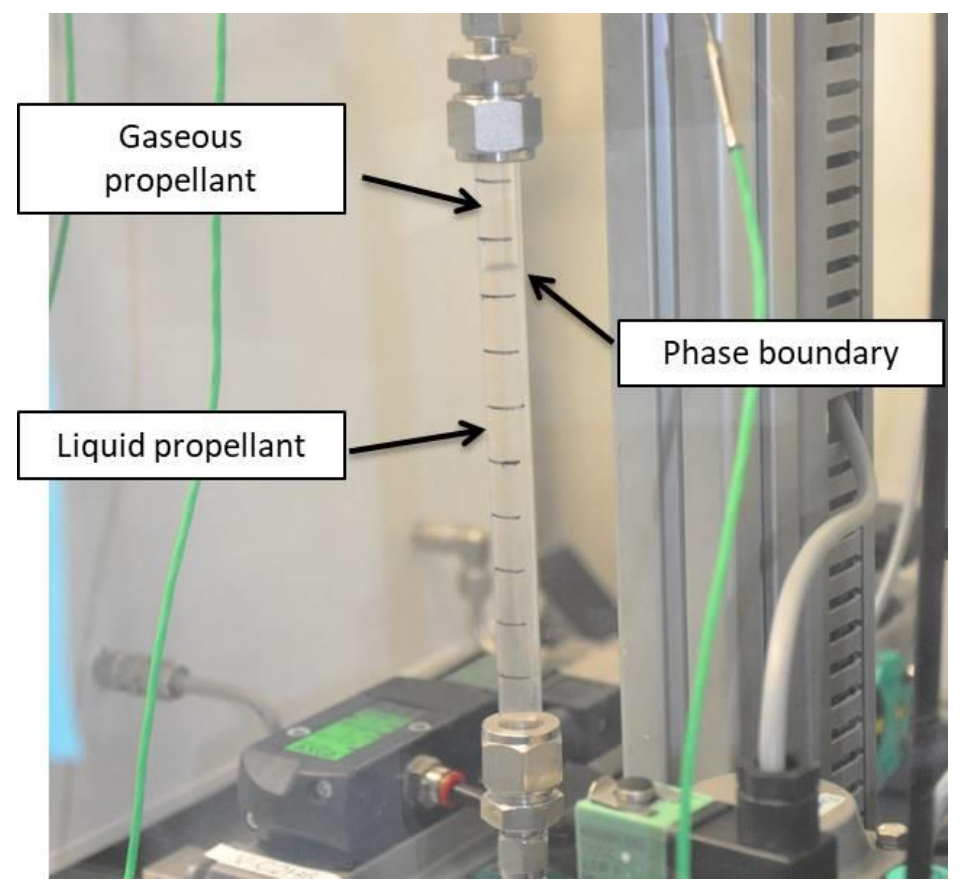

Fig. 26: Liquefied $\mathrm{N}_{2} \mathrm{O} / \mathrm{C}_{2} \mathrm{H}_{6}$ propellant in miscibility setup

\section{Summary}

The paper provides an overview of DLR's activities and work packages concerning premixed green propellants consisting of nitrous oxide and hydrocarbons. Those propellants are also known as nitrous oxide fuel blends (NOFB) or hydrocarbons mixed with nitrous oxide (HyNOx). The investigations are carried out in the framework of DLR's Future Fuels project. A subproject of Future Fuels is dedicated to green propellant consisting of premixed nitrous oxide $\left(\mathrm{N}_{2} \mathrm{O}\right)$ and ethene $\mathrm{C}_{2} \mathrm{H}_{4}$ or ethane $\mathrm{C}_{2} \mathrm{H}_{6}$.

The activities are divided into five main parts: 1) Investigations of the propellant performance in an experimental rocket combustor; 2) Analysis of the ignition and flame propagation processes as well as the development of flame arresters; 3) Investigation, derivation and reduction of suitable reaction mechanisms to calculate typical flame parameters and to be used in numerical simulations; 4) CFD simulations of the transient combustion process inside an ignition test section and later on in the rocket combustor and 5) Liquid propellant miscibility investigations.

In the course of the project hundreds of combustion, ignition and flame arrester test were performed. The propellant's performance and occurring heat loads to the combustion chamber walls were analyzed. Further on porous flame arresters were tested and their ability to quench the $\mathrm{N}_{2} \mathrm{O} / \mathrm{C}_{2} \mathrm{H}_{4}$ flame was examined and compared to the quenching performance of capillaries. Moreover reaction mechanism for $\mathrm{N}_{2} \mathrm{O} / \mathrm{C}_{2} \mathrm{H}_{4}$ were derived and used to simulate the flame propagation process by using commercial CFD tools. Currently liquid propellant miscibility investigations started, these investigations will be continued within the framework of an ESA project.

A spotlight on some of the project's results is briefly discussed in this paper, for detailed information the given references should be taken into account.

\section{References}

[1] R. L. Sackheim and R. K. Masse, "Green Propulsion Advancement: Challenging the Maturity of Monopropellant Hydrazine," Journal of Propulsion and Power, vol. 30, no. 2, pp. 265-276, 2014, doi: 10.2514/1.b35086.

[2] A. S. Gohardani et al., "Green space propulsion: Opportunities and prospects," Progress in Aerospace Sciences, vol. 71, no. 1, pp. 128-149, 2014, doi: 10.1016/j.paerosci.2014.08.001.

[3] M. Persson, K. Anflo, A. Dinardi, and J. Bahu, "A Family of Thrusters for ADN-Based Monopropellant LMP103S," in 48th AIAA/ASME/SAE/ASEE Joint Propulsion Conference \& Exhibit, Atlanta, Georgia. 
[4] M. Persson, K. Anflo, and P. Friedhoff, "Flight Heritage of Ammonium Dinitramide (ADN) Based High Performance Green Propulsion (HPGP) Systems," Prop., Explos., Pyrotech., vol. 44, no. 9, pp. 1073-1079, 2019, doi: 10.1002/prep.201900248.

[5] P. Friedhoff, A. Hawkins, J. Carrico, J. Dyer, and K. Anflo, "In-Orbit Operation and Performance of Ammonium Dinitramide (ADN) Based High Performance Green Propulsion (HPGP) Systems," in 53rd AIAA/SAE/ASEE Joint Propulsion Conference, AIAA Propulsion and Energy Forum, 2017.

[6] M. Negri et al., "New technologies for ammonium dinitramide based monopropellant thrusters - The project RHEFORM," Acta Astronautica, vol. 143, no. 1, pp. 105-117, 2018, doi: 10.1016/j.actaastro.2017.11.016.

[7] M. Ventura and G. Garboden, "A Brief History of Concentrated Hydrogen Peroxide Uses," General Kinetics, LLC, Aliso Viejo, CA, Jun. 1999.

[8] D. Baker, NASA Mercury, 1956-1963 (all models): Owners' workshop manual : an insight into the design and engineering of Project Mercury - America's first manned space programme. Somerset, UK: Haynes, 2017.

[9] A. Cervone et al., "Development of Hydrogen Peroxide Monopropellant Rockets," in 42nd AIAA/ASME/SAE/ASEE Joint Propulsion Conference \& Exhibit, 9.-12. July 2006, Sacramento, California, USA.

[10] F. Lauck, J. Witte, M. Negri, D. Freudenmann, and S. Schlechtriem, "Design and first results of an injector test setup for green hypergolic propellants," in AIAA Propulsion and Energy 2019 Forum, p. 163.

[11] B. Greene, D. L. Baker, and W. Frazier, "Hydrogen Peroxide Accidents and Incidents: What We Can Learn From History," in 32nd PDCS Joint JANNAF Meeting; 26-30 Jul. 2004.

[12] R. Bruce, G. Taylor, R. Ross, and D. Beckmeyer, "Propulsion Ground Testing with High Test PeroxideLessons Learned," in 22nd AIAA Aerodynamic Measurement Technology and Ground Testing Conference, St. Louis, Missouri, 2002.

[13] R. Masse, M. Allen, R. Spores, and E. A. Driscoll, "AF-M315E Propulsion System Advances and Improvements," in 52nd AIAA/SAE/ASME Joint Propulsion Conference, 25.-27. July 2017, Salt Lake City, Utah, USA, 2017.

[14] R. A. Spores, "GPIM AF-M315E Propulsion System," in 51st AIAA/ SAE/ ASEE Joint Propulsion Conference, 27.-29. July 2015, Orlando, Florida, USA, Orlando, FL, 2015.

[15] R. Amrousse, T. Katsumi, N. Azuma, and K. Hori, "Hydroxylammonium nitrate (HAN)-based green propellant as alternative energy resource for potential hydrazine substitution: From lab scale to pilot plant scale-up," Combustion and Flame, vol. 176, no. 1, pp. 334-348, 2017, doi: 10.1016/j.combustflame.2016.11.011.

[16] K. Hori, "Lessons Learned in the Thruster Tests of HAN," in Springer Aerospace Technology, Chemical Rocket Propulsion: A Comprehensive Survey of Energetic Materials, Cham, s.l.: Springer International Publishing, 2017, pp. 801-818.

[17] U. Gotzig, "Challenges and Economic Benefits of Green Propellants for Satellite Propulsion," in 7th European Conference for Aeronautics and Space Sciences (EUCASS), 03. - 06. Jul. 2017, Milano, Italy, 2017.

[18] N.-E. Harmansa, G. Herdrich, and S. Fasoulas, "Development of a Water Propulsion System for Small Satellites," in 68th International Astronautical Congress 25.-29.09.2017.

[19] N.-E. Harmansa, G. Herdrich, S. Fasoulas, and U. Gotzig, "Development of a water electrolysis propulsion system for small satellites," in Space Propulsion Conference 14.-18.05.2018, Sevilla, Spain.

[20] M. Gregory, D. J. Fisher, C. Mungas, and B. Carryer, "Nitrous Oxide Fuel Blend Monopropellant, US 2009/0133788 A1," US2009 0133788 A1, USA United States patent US20090133788 A1, May 28, 2009.

[21] G. Mungas, "NOFBX ${ }^{\mathrm{TM}}$ Propulsion Overview: Propulsion Challenges for Commercial Reusable Space Vehicles," in 49th AIAA/ASME/ SAE/ ASEE Joint Propulsion Conference, 15. - 17. July, 2013, San Jose, California, USA, San Jose, CA, 2013.

[22] G. Mungas, D. J. Fisher, V. Joanne, and M. Villa, "NOFBX' ${ }^{\mathrm{TM}}$ single stage to Orbit Mars Ascent Vehicle," in IEEE Aerospace Conference 2012, pp. 1-11.

[23] G. Mungas, M. Vozoff, and B. Rishikof, "NOFBX: A new non-toxic, Green propulsion technology with high performance and low cost," in 63rd International Astronautical Congress, 1-5 October 2012, Naples, Italy, 2012.

[24] M. Gruss, DARPA Scraps Plan To Launch Small Sats from F-15 Fighter Jet. [Online]. Available: http:// spacenews.com/darpa-airborne-launcher-effort-falters/.

[25] J. D. Clark, Ignition! An informal history of liquid rocket propellants. New Brunswick, N.J, Ann Abor, Mich.: Rutgers University Press; UMI Books on Demand, 2017.

[26] A. E.H.J. Mayer, I. Waugh, and M. Poucet, "European Fuel Blend, Final Report: ESTEC Contract Number 4000113544/15/NL/AD,” TNO 2018 R10640, Jun. 2018. 
[27] A. E.H.J. Mayer et al., "European Fuel Blend development for in-space propulsion," in Space Propulsion Conference 14.-18.05.2018, Sevilla, Spain.

[28] I. Waugh, E. Moore, J. Macfarlane, A. Watts, and A. E.H.J. Mayer, "Testing of a novel nitrous-oxide and ethanol fuel blend," in Space Propulsion Conference 14.-18.05.2018, Sevilla, Spain.

[29] H. K. Ciezki et al., "Advanced Propellants for Space Propulsion - A Task within the DLR Interdisciplinary Project "Future Fuels"," in 8th European Conference for Aeronautics and Space Sciences (EUCASS), 1. -4. July 2019, Madrid, Spain. Accessed: Sep. 3 2019. [Online]. Available: http://www.eucass2019.eu/

[30] T. Pregger et al., "Future Fuels-Analyses of the Future Prospects of Renewable Synthetic Fuels," Energies, vol. 13, no. 1, p. 138, 2020, doi: 10.3390/en13010138.

[31] H. K. Ciezki et al., "50 Years of Test Complex M11 in Lampoldshausen - Research on Space Propulsion Systems for Tomorrow," in 7th European Conference for Aeronautics and Space Sciences (EUCASS), 03. - 06. Jul. 2017, Milano, Italy, 2017. Accessed: Aug. 142018.

[32] M. Wilhelm et al., "Test complex M11: Research on Future Orbital Propulsion Systems and Scramjet engines," in 70th International Astronautical Congress, Washington, USA, 2019.

[33] L. Werling, N. Perakis, S. Müller, A. Hauk, H. Ciezki, and S. Schlechtriem, "Hot firing of a N2O/C2H4 premixed green propellant: First combustion tests and results," in Space Propulsion Conference, 1.-5. May 2016, Rome, Italy. Accessed: Feb. 92018.

[34] N. Perakis, L. Werling, H. Ciezki, and S. Schlechtriem, "Numerical Calculation of Heat Flux Profiles in a N2O/C2H4 Premixed Green Propellant Combustor using an Inverse Heat Conduction Method," in Space Propulsion Conference, 1.-5. May 2016, Rome, Italy.

[35] L. Werling, M. Hassler, F. Lauck, H. K. Ciezki, and S. Schlechtriem, "Experimental Performance Analysis (c* $\& c^{*}$ Efficiency) of a Premixed Green Propellant consisting of $\mathrm{N} 2 \mathrm{O}$ and $\mathrm{C} 2 \mathrm{H} 4$, " in 53rd AIAA/SAE/ASEE Joint Propulsion Conference, 10-12 July 2017, Atlanta, GA, USA, 2017.

[36] L. Werling, P. Bätz, H. Ciezki, and S. Schlechtriem, "Influence of combustion chamber size ( $\left.L^{*}\right)$ on characteristic exhaust velocity (c*) for a N2O/C2H4 premixed green propellant," in Space Propulsion Conference 14.-18.05.2018, Sevilla, Spain. Accessed: Aug. 172018.

[37] L. Werling, T. Hörger, H. K. Ciezki, and S. Schlechtriem, "Experimental and Theoretical Analysis of the Combustion Efficiency and the Heat Loads on a N2O/C2H4 Green Propellant Combustion Chamber," in 8th European Conference for Aeronautics and Space Sciences (EUCASS), 1.-4. July 2019, Madrid, Spain.

[38] L. Werling, N. Perakis, B. Hochheimer, H. Ciezki, and S. Schlechtriem, "Experimental Investigations based on a Demonstrator Unit to analyze the Combustion Process of a Nitrous Oxide/Ethene Premixed Green Bipropellant," in 5th CEAS Air \& Space Conference, 7.-11. September 2015, Delft, The Netherlands.

[39] S. Gordon and B. McBride, Computer Program for Calculation of Complex Chemical Equilibrium Compositions and Applications: NASA Reference Publication 1311. I. Analysis, 1996.

[40] L. Werling, Y. Jooß, M. Wenzel, H. K. Ciezki, and S. Schlechtriem, "A premixed green propellant consisting of $\mathrm{N} \$ 2 \$ \mathrm{O}$ and $\mathrm{C} \$ 2 \$ \mathrm{H} \$ 4 \$$ : Experimental analysis of quenching diameters to desing flashback arresters," Int J Energetic Materials Chem Prop, vol. 17, no. 3, pp. 241-262, 2018, doi: 10.1615/IntJEnergeticMaterialsChemProp.2019027950.

[41] L. Werling, F. Lauck, D. Freudenmann, N. Weber, H. Ciezki, and S. Schlechtriem, "Experimental investigation of the ignition, flame propagation and flashback behavior of a premixed green propellant consisting of $\mathrm{N} 2 \mathrm{O}$ and $\mathrm{C} 2 \mathrm{H} 4$," in 7th European Conference for Aeronautics and Space Sciences, (EUCASS), 03. - 06. Jul. 2017, Milano, Italy.

[42] P. B. Venkatesh, J. D’Entremont, S. E. Meyer, S. P. M. Bane, and M. C. Grubelich, "High-Pressure Combustion and Deflagration-to-Detonation Transition in Ethylene/Nitrous Oxide Mixtures," in 8th U.S. National Combustion Meeting, At Park City, Utah.

[43] P. B. Venkatesh, J. T. Graziano, S. P. Bane, S. Meyer, and M. C. Grubelich, "Deflagration-to-Detonation Transition in Nitrous Oxide-Ethylene Mixtures and its Application to Pulsed Propulsion Systems," in 55th AIAA Aerospace Sciences Meeting, Grapevine, Texas. Accessed: Feb. 92018.

[44] S. R. Turns, An introduction to combustion: Concepts and applications, 2nd ed. Boston: McGraw-Hill; WCB/ McGraw-Hill, 2000.

[45] K. K. Kuo, Principles of Combustion, 2nd ed. Hoboken, NJ: Wiley, 2005.

[46] C. R. Ferguson and J. C. Keck, "On laminar flame quenching and its application to spark ignition engines," in 1977, pp. 197-205.

[47] D. B. Spalding, "A theory of inflammability limits and flame-quenching," Proceedings of the Royal Society of London A: Mathematical, Physical and Engineering Sciences, vol. 240, no. 1220, pp. 83-100, 1957, doi: 10.1098/rspa.1957.0068. 
[48] T. Poinsot and D. Veynante, Theoretical and Numerical Combustion, 3rd ed. Paris: CNRS, 2011.

[49] J. Jarosinsky and B. Veyssiere, Combustion phenomena: Selected mechanisms of flame formation, propagation, and extinction. Boca Raton: CRC Press, 2009.

[50] M. Hattwig and H. Steen, Handbook of explosion prevention and protection. Weinheim: Wiley-VCH, 2004.

[51] D. Nield and A. Bejan, "Mechanics of Fluid Flow Through a Porous Medium," in Convection in porous media, D. A. Nield and A. Bejan, Eds., Cham: Springer International Publishing, 2017, pp. 1-29.

[52] C. Naumann, C. Janzer, and U. Riedel, "Ethane / Nitrous Oxide Mixtures as a Green Propellant to Substitute Hydrazine: Validation of Reaction Mechanism," in 9th European Combustion Meeting (ECM), 14.17.04.2019, Lisbon, Portugal.

[53] C. Naumann, T. Kick, T. Methling, M. Braun-Unkhoff, and U. Riedel, "Ethene/Nitrous Oxide Mixtures as green Propellant to substitute Hydrazine: Reaction Mechanism validation," Int J Energetic Materials Chem Prop, vol. 19, no. 1, pp. 65-71, 2020, doi: 10.1615/IntJEnergeticMaterialsChemProp.2020028133.

[54] T. Kick, J. H. Starke, and C. Naumann, "Green Propellant Substituting Hydrazine: Investigation of Ignition Delay Time and Laminar Flame Speed of Ethene/Dinitrogen Oxide Mixtures," in 8th European Combustion Meeting (ECM), 18.-21.04.2017, Dubrovnik, Croatia.

[55] G. P. Smith et al., GRI-Mech 3.0. http://www.me.berkeley.edu/gri_mech/.

[56] T. Methling, M. Braun-Unkhoff, and U. Riedel, "A novel linear transformation model for the analysis and optimisation of chemical kinetics," Combustion Theory and Modelling, vol. 21, no. 3, pp. 503-528, 2017, doi: 10.1080/13647830.2016.1251616.

[57] O. A. Powell, P. Papas, and C. Dreyer, "Laminar Burning Velocities for Hydrogen-, Methane-, Acetylene-, and Propane-Nitrous Oxide Flames," Combustion Science and Technology, vol. 181, no. 7, pp. 917-936, 2009, doi: 10.1080/00102200902817066.

[58] T. Kathrotia, U. Riedel, A. Seipel, K. Moshammer, and A. Brockhinke, "Experimental and numerical study of chemiluminescent species in low-pressure flames," Appl. Phys. B, vol. 107, no. 3, pp. 571-584, 2012, doi: 10.1007/s00340-012-5002-0.

[59] D. G. Goodwin, H. K. Moffat, and R. L. Speth, CANTERA, Version 2.2.1: An object- oriented software toolkit for chemical kinetics, thermodynamics, and transport processes. 